Electronic Supplementary information for

\title{
Development of a series of fluorescent probes for the early diagnostic imaging of sulfur mustard poisoning
}

Wenqi Meng, ${ }^{\mathrm{a}, \mathrm{b}}$ Mingxue Sun, ${ }^{\mathrm{a}}$ Qingqiang Xu, ${ }^{\mathrm{a}}$ Jinfeng Cen ${ }^{\mathrm{a}}$, Yongbing Cao, ${ }^{*}, \mathrm{c}$ Zhenjiang Li ${ }^{*}, \mathrm{~b}$,

and Kai Xiao*,a

${ }^{a}$ Lab of Toxicology \& Pharmacology, Faculty of Naval Medicine, Second Military Medical University, Shanghai, China. E-mail: kaixiaocn@hotmail.com (K. Xiao).

b State Key Laboratory of Materials-Oriented Chemical Engineering, College of Biotechnology and Pharmaceutical Engineering, Nanjing Tech University, Nanjing, China. E-mail: zjli@njtech.edu.cn (Z. Li).

c Department of Vascular Disease, Shanghai TCM-Integrated Hospital, Shanghai University of Traditional Chinese Medicine, Shanghai, China. E-mail: ybcao@vip.sina.com (Y. Cao) 


\section{Synthesis and characterization of compounds}

\section{Synthesis of compound 2}

A solution of compound $1(5.0 \mathrm{~g}, 0.02 \mathrm{~mol})$ in water $(65 \mathrm{~mL})$ was stirred in a sealed vessel at $220^{\circ} \mathrm{C}$ for $6 \mathrm{~h}$. After cooling, the mixture was filtered, and the solid was concentrated in vacuo to obtain 3,6-dihydroxy-9H-xanthen-9-one 2 (4.4 g, 96\%) as a light yellow solid.

\section{Synthesis of compound 3}

To a solution of compound 2 (3.0 g, $0.01 \mathrm{~mol})$ in DCM (300 mL) and pyridine $(12 \mathrm{~mL})$, trifluoromethanesulfonic anhydride $\left(\mathrm{Tf}_{2} \mathrm{O}, 6.5 \mathrm{~mL}\right)$ in $\mathrm{DCM}(20 \mathrm{~mL})$ was added dropwise at $0{ }^{\circ} \mathrm{C}$. The mixture stirred at room temperature for $2 \mathrm{~h}$. The mixture was quenched with water. The DCM layer was washed with $1 \mathrm{~N} a q \mathrm{HCl}$ and brine, dried over $\mathrm{Na}_{2} \mathrm{SO}_{4}$, and concentrated to obtain compound $3(5.8 \mathrm{~g}, 89 \%)$ as a light yellow solid.

\section{Synthesis of compound 4}

Diethylamine (4.5 g, $60.97 \mathrm{mmol}$ ) was added to a solution of compound 3 (3.0 g, $6.09 \mathrm{mmol})$ in DMSO $(17 \mathrm{~mL})$. The mixture was stirred at $90{ }^{\circ} \mathrm{C}$ for $18 \mathrm{~h}$. The mixture was dissolved in EA and slowly added to water. The organic layer was washed with water and brine, dried over $\mathrm{Na}_{2} \mathrm{SO}_{4}$, and evaporated in vacuo to obtain crude 5 . The crude product was purified by silica gel chromatography (PE:EA=10:1 to $4: 1$ ) to obtain compound 5 (700 mg, 33\%) as a yellow solid. 


\section{Synthesis of OxSM-1}

Lawesson's Reagent (1.1 g, $2.73 \mathrm{mmol})$ was added to a solution of compound 5 (770 mg, $2.27 \mathrm{mmol})$ in toluene $(20 \mathrm{~mL})$. The mixture stirred at $90{ }^{\circ} \mathrm{C}$ for $20 \mathrm{~min}$. The mixture was dissolved in EA, washed with water and brine, dried over $\mathrm{Na}_{2} \mathrm{SO}_{4}$, and evaporated in vacuo to obtain crude OxSM-1. The crude product was purified by silica gel chromatography (100\% DCM) to obtain OxSM-1 (600 mg, 74\%) as a red solid. ${ }^{1} \mathrm{H}$ NMR (400 MHz, $\left.\mathrm{CDCl}_{3}\right) \delta 8.66(\mathrm{~d}, J=9.3 \mathrm{~Hz}, 2 \mathrm{H}), 6.70(\mathrm{dd}, J=9.3,2.6 \mathrm{~Hz}, 2 \mathrm{H}), 6.40$ $(\mathrm{d}, J=2.5 \mathrm{~Hz}, 2 \mathrm{H}), 3.47(\mathrm{q}, J=7.1 \mathrm{~Hz}, 8 \mathrm{H}), 1.25(\mathrm{t}, J=7.1 \mathrm{~Hz}, 12 \mathrm{H}) .{ }^{13} \mathrm{C}$ NMR $(101$ $\left.\mathrm{MHz}, \mathrm{CDCl}_{3}\right) \delta 195.37,153.42,152.53,132.01,119.67,110.25,95.37,44.91,12.64$. HRMS (ESI, $m / z$ ): Calcd. for $\left[\mathrm{C}_{21} \mathrm{H}_{26} \mathrm{~N}_{2} \mathrm{OS}+\mathrm{H}\right]^{+}, 355.1844$; Found, 355.2010.

\section{Synthesis of compound 5}

To a solution of compound $3(180 \mathrm{mg}, 0.36 \mathrm{mmol})$ in DMSO (2 mL), morpholine (318 mg, $3.65 \mathrm{mmol}$ ) was added. The mixture stirred at $90{ }^{\circ} \mathrm{C}$ for $15 \mathrm{~h}$ under $\mathrm{N}_{2}$. After cooling to room temperature, the reaction was quenched with water. The precipitate was collected, washed with saturated aqueous $\mathrm{Na}_{2} \mathrm{CO}_{3}$ and water to give the crude product compound $\mathbf{5}$ (200 $\mathrm{mg}$, crude) as a light yellow solid.

\section{Synthesis of OxSM-2}

Lawesson's Reagent (265 mg, $0.65 \mathrm{mmol}$ ) was added to a solution of compound 5 (200 mg, crude) in dry toluene $(8 \mathrm{~mL})$. The mixture stirred at $80{ }^{\circ} \mathrm{C}$ for $20 \mathrm{~min}$. The 
reaction mixture was directly purified by flash chromatography (silica gel, $1 \%$ to $4 \%$ MeOH in DCM) to obtain OxSM-2 (37 mg, 26\% for 2 steps) as a red solid. ${ }^{1} \mathrm{H}$ NMR $\left(400 \mathrm{MHz}, \mathrm{CDCl}_{3}\right) \delta 8.67(\mathrm{~d}, J=9.2 \mathrm{~Hz}, 2 \mathrm{H}), 6.91(\mathrm{dd}, J=9.2,2.3 \mathrm{~Hz}, 2 \mathrm{H}), 6.63(\mathrm{~d}, J$ $=2.2 \mathrm{~Hz}, 2 \mathrm{H}), 3.93-3.82(\mathrm{~m}, 8 \mathrm{H}), 3.46-3.32(\mathrm{~m}, 8 \mathrm{H}) .{ }^{13} \mathrm{C} \mathrm{NMR}\left(101 \mathrm{MHz}, \mathrm{CDCl}_{3}\right) \delta$ 197.92, 131.66, 112.25, 98.87, 77.29, 77.03, 76.71, 66.46, 47.32. HRMS (ESI, $m / z)$ : Calcd. for $\left[\mathrm{C}_{21} \mathrm{H}_{22} \mathrm{~N}_{2} \mathrm{O}_{3} \mathrm{~S}-\mathrm{H}\right]^{-}, 383.1429$; Found, 383.1419.

\section{Synthesis of compound 6}

Pyrrolidine $(5.8 \mathrm{~g}, 81.69 \mathrm{mmol})$ was added to a solution of compound 3 (4.0 g, $8.13 \mathrm{mmol})$ in DMSO $(30 \mathrm{~mL})$. The mixture stirred at $90{ }^{\circ} \mathrm{C}$ for 30 min under $\mathrm{N}_{2}$. The mixture was then dissolved in DCM and slowly added to water. The organic layer was washed with water, sat.aq. $\mathrm{Na}_{2} \mathrm{CO}_{3}$ and brine, dried over $\mathrm{Na}_{2} \mathrm{SO}_{4}$, and evaporated in vacuo to obtain crude $\mathbf{6}$. The crude product was purified by flash chromatography (silica gel, $1 \%$ to $2 \% \mathrm{MeOH}$ in DCM) to obtain compound $6(380 \mathrm{mg}, 14 \%)$ as a light yellow solid.

\section{Synthesis of OxSM-3}

Lawesson's Reagent (545 mg, $1.34 \mathrm{mmol}$ ) was added to a solution of 3,6di(pyrrolidin-1-yl)-9H-xanthen-9-one 5 (380 mg, $1.12 \mathrm{mmol})$ in dry toluene $(5 \mathrm{~mL})$. The mixture stirred at $80{ }^{\circ} \mathrm{C}$ for $20 \mathrm{~min}$. The mixture was then filtered to obtain a red solid. The solid was purified by flash chromatography (silica gel, 1\% MeOH in DCM) to obtain OxSM-3 (55 mg, 14\%) as a red solid. ${ }^{1} \mathrm{H}$ NMR $\left(400 \mathrm{MHz}, \mathrm{CDCl}_{3}\right) \delta 8.70(\mathrm{~d}$, 
$J=9.1 \mathrm{~Hz}, 2 \mathrm{H}), 6.65(\mathrm{dd}, J=9.1,2.2 \mathrm{~Hz}, 2 \mathrm{H}), 6.37(\mathrm{~d}, J=2.2 \mathrm{~Hz}, 2 \mathrm{H}), 3.44(\mathrm{t}, J=6.6$ $\mathrm{Hz}, 8 \mathrm{H}), 2.11-2.06(\mathrm{~m}, 8 \mathrm{H}) .{ }^{13} \mathrm{C} \mathrm{NMR}\left(101 \mathrm{MHz}, \mathrm{CDCl}_{3}\right) \delta 153.04,151.91,132.08$, 120.20, 111.23, 96.38, 48.29, 25.42. HRMS (ESI, $m / z$ ): Calcd. for $\left[\mathrm{C}_{21} \mathrm{H}_{22} \mathrm{~N}_{2} \mathrm{OS}-\mathrm{H}\right]^{-}$, 349.1375; Found, 349.1900.

\section{Synthesis of compound 8}

A solution of compound $7(10.0 \mathrm{~g}, 58.1 \mathrm{mmol})$, ethyl iodide $(22.6 \mathrm{~g}, 145.0 \mathrm{mmol})$ and $\mathrm{K}_{2} \mathrm{CO}_{3}(16.0 \mathrm{~g}, 116.2 \mathrm{mmol})$ in $100 \mathrm{~mL} \mathrm{ACN}$ was stirred under reflux overnight. The mixture was filtered, and the solution was concentrated in vacuo to give the crude product, which was purified by silica gel column chromatography eluted with PE to give compound $\mathbf{8}(9.0 \mathrm{~g}, 68 \%)$ as a yellow oil.

\section{Synthesis of compound 9}

A solution of compound $8(2.0 \mathrm{~g}, 8.8 \mathrm{mmol})$ and $40 \% \mathrm{CHO}(5 \mathrm{~mL})$ in $\mathrm{AcOH}$ (20 mL) stirred at $80{ }^{\circ} \mathrm{C}$ overnight. The mixture was then poured into ice water. The $\mathrm{pH}$ of the mixture was adjusted to 8 by adding $a q$. sat. $\mathrm{NaOH}$. Then, the mixture was extracted with EA and washed with brine, and the organic layer was concentrated in vacuo to give compound $9(2.3 \mathrm{~g}, 90 \%)$ as a red oil.

\section{Synthesis of compound 10}

To a solution of compound $9(1.0 \mathrm{~g}, 2.1 \mathrm{mmol})$ in $20 \mathrm{~mL}$ THF, t-BuLi (3.3 ml, $5.3 \mathrm{mmol}$ ) was added slowly at $-60{ }^{\circ} \mathrm{C}$ under $\mathrm{N}_{2}$, and then the mixture stirred at $-60{ }^{\circ} \mathrm{C}$ 
for $2 \mathrm{~h}$. To this mixture was added $\mathrm{Me}_{2} \mathrm{SiCl}_{2}(0.4 \mathrm{~g}, 3.1 \mathrm{mmol})$ at $-60{ }^{\circ} \mathrm{C}$, followed by stirring at RT overnight. The mixture was quenched with $1 \mathrm{~N} \mathrm{HCl}$, and the $\mathrm{pH}$ of the mixture was adjusted to 7 by adding aq. sat. $\mathrm{NaHCO}_{3}$. The mixture was extracted with EA and washed with brine, and the organic layer was concentrated in vacuo to give compound $\mathbf{1 0}(1.2 \mathrm{~g}$, crude) as a yellow oil.

\section{Synthesis of compound 11}

To a solution of compound $\mathbf{1 0}(1.2 \mathrm{~g}$, crude) in $20 \mathrm{~mL}$ of acetone was added $\mathrm{KMnO}_{4}(1.6 \mathrm{~g}, 10.0 \mathrm{mmol})$ slowly at $0{ }^{\circ} \mathrm{C}$ under $\mathrm{N}_{2}$, then the mixture stirred at $0{ }^{\circ} \mathrm{C}$ for $2 \mathrm{~h}$. The mixture was filtered, and the solution was concentrated in vacuo to give the crude product, which was purified by silica gel column chromatography eluted with PE:EA=10:1 to give compound $11(70.1 \mathrm{mg}, 9 \%)$ as a yellow oil.

\section{Synthesis of SiNIR-SM}

A solution of $11(50.1 \mathrm{mg}, 0.1 \mathrm{mmol})$ and Lawesson's Reagent (106.2 mg, 0.2 mmol) in $5 \mathrm{~mL}$ toluene was stirred at $90{ }^{\circ} \mathrm{C}$ for $1 \mathrm{~h}$ under $\mathrm{N}_{2}$. The mixture was purified by silica gel column chromatography eluted with PE EA=10:1 to give SiNIR-SM (20.0 mg, 39\%) as a green solid. ${ }^{1} \mathrm{H}$ NMR $\left(400 \mathrm{MHz}, \mathrm{CDCl}_{3}\right) \delta 8.78(\mathrm{~d}, J=9.1 \mathrm{~Hz}, 2 \mathrm{H})$, 6.79-6.60 (m, 4H), $3.46(\mathrm{q}, J=7.1 \mathrm{~Hz}, 8 \mathrm{H}), 1.23(\mathrm{t}, J=7.1 \mathrm{~Hz}, 12 \mathrm{H}), 0.43(\mathrm{~s}, 6 \mathrm{H}) .{ }^{13} \mathrm{C}$ NMR $\left(101 \mathrm{MHz}, \mathrm{CDCl}_{3}\right) \delta 190.79,162.36,148.89,136.05,135.79,112.86,44.72$, 12.78. HRMS (ESI, $m / z$ ): Calcd. for $\left[\mathrm{C}_{23} \mathrm{H}_{32} \mathrm{~N}_{2} \mathrm{SSi}+\mathrm{H}\right]^{+}$, 397.2134; Found, 397.2317. 

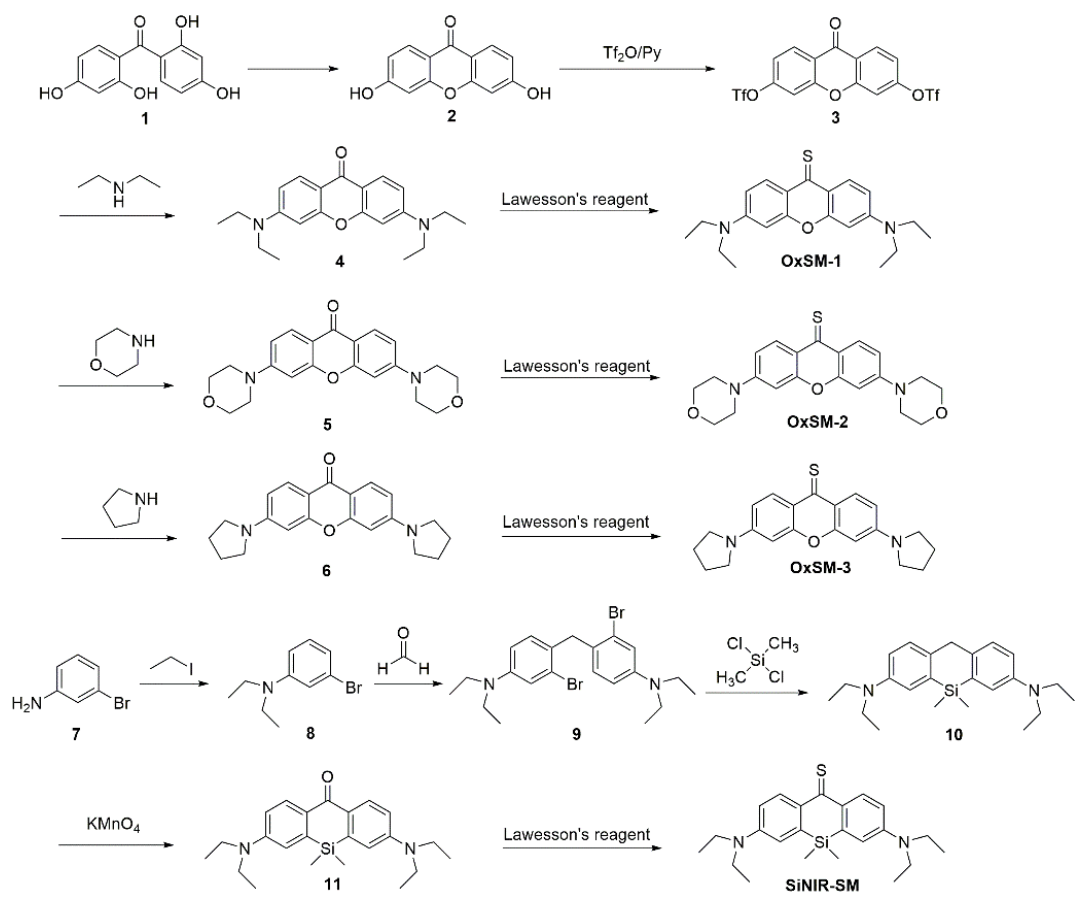

Scheme S1. Synthetic route for the fluorescent probes OxSM-1, OxSM-2, OxSM-3, and SiNIR-SM. 


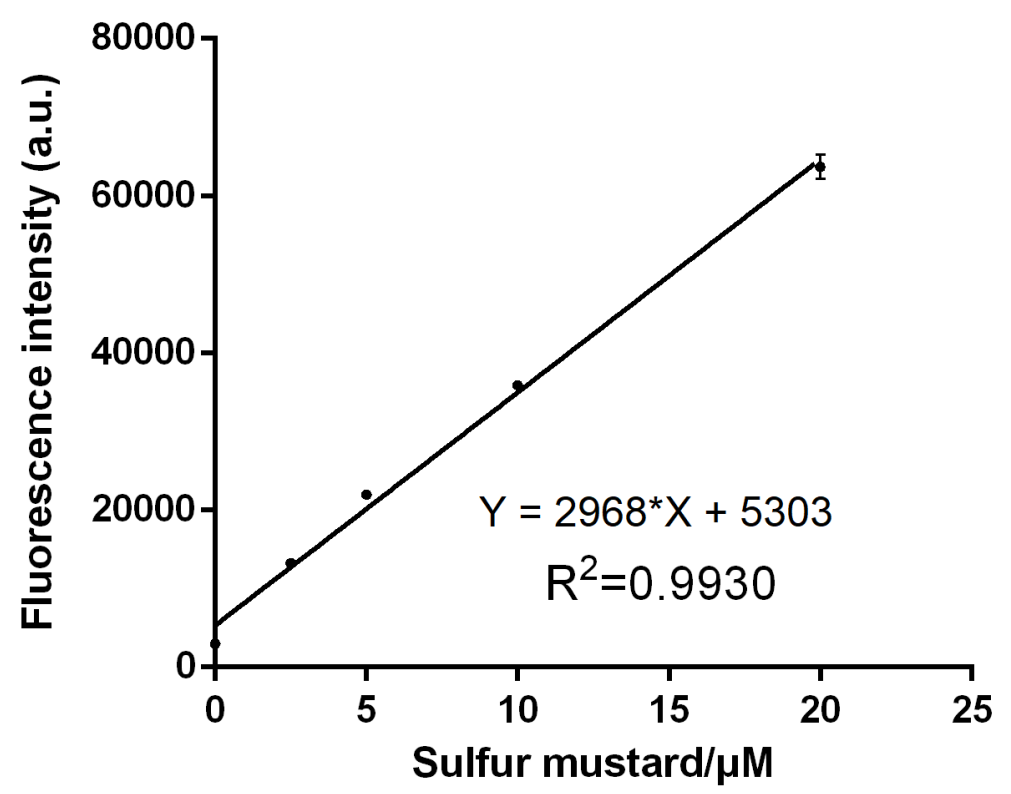

Figure S1. The linear relationship between the emission intensity and the concentration of sulfur mustard $(0-20 \mu \mathrm{M})$ in PBS buffer. 
A

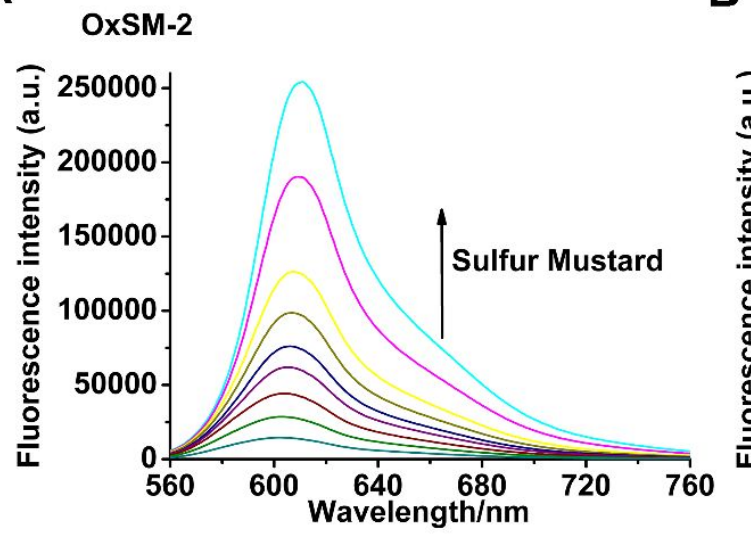

B

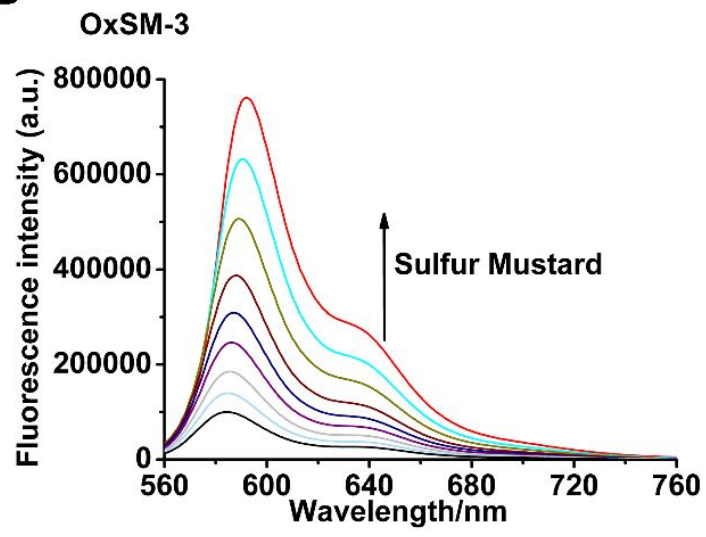

Figure S2. Fluorescence spectral changes of (A) OxSM-2, (B) OxSM-3 upon the addition of sulfur mustard $(0-200 \mu \mathrm{M})$. All the data were collected using a probe concentration of $10 \mu \mathrm{M}$ in PBS buffer $\left(20 \mathrm{mM}, \mathrm{pH}=7.4,20 \% \mathrm{CH}_{3} \mathrm{CN}\right)$ at $37{ }^{\circ} \mathrm{C}$ for 1 h. The excitation wavelength was $550 \mathrm{~nm}$. 

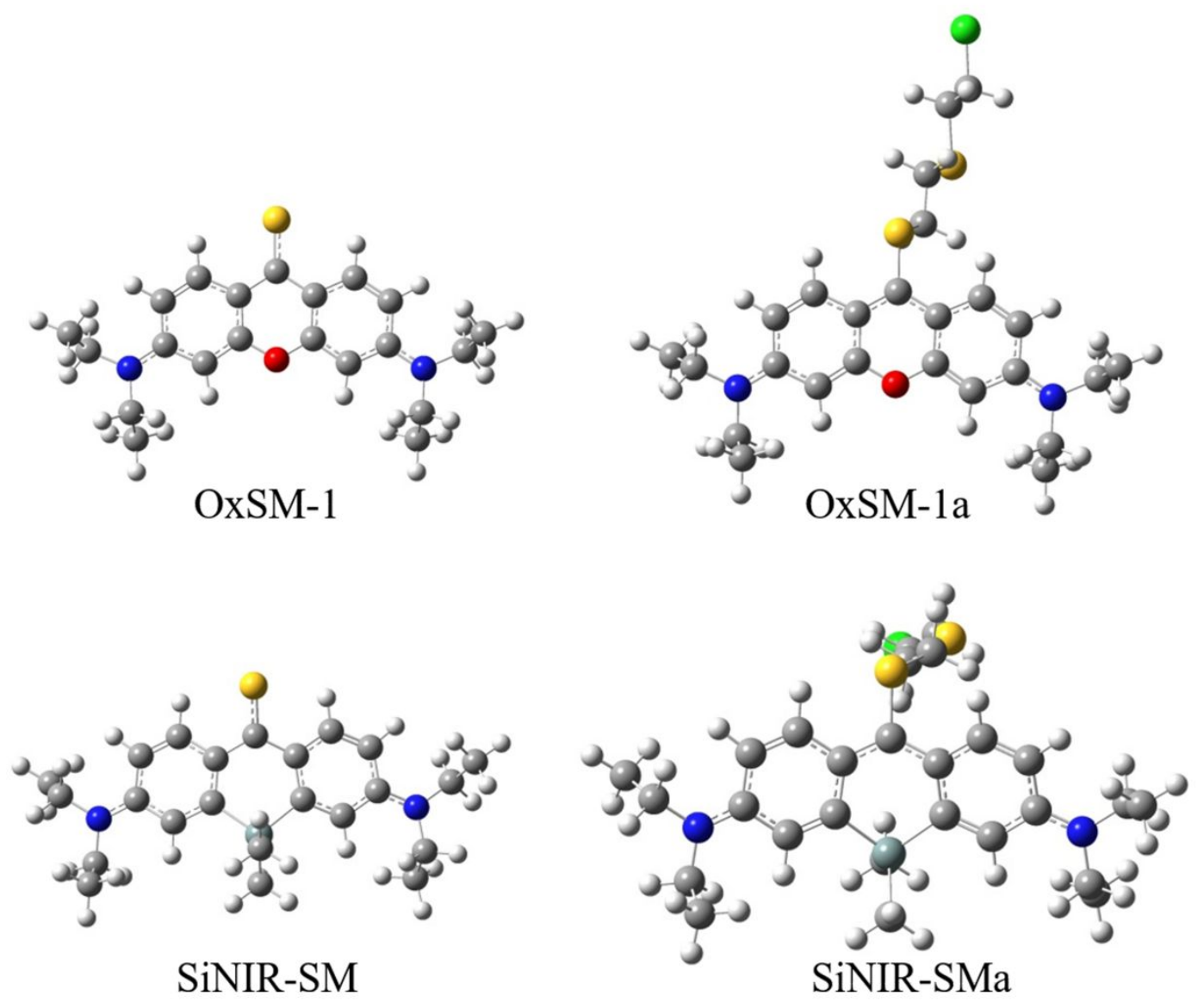

Figure S3. Optimized structures of the ground states of OxSM-1, OxSM-1a, SiNIRSM and SiNIR-SMa. 
A
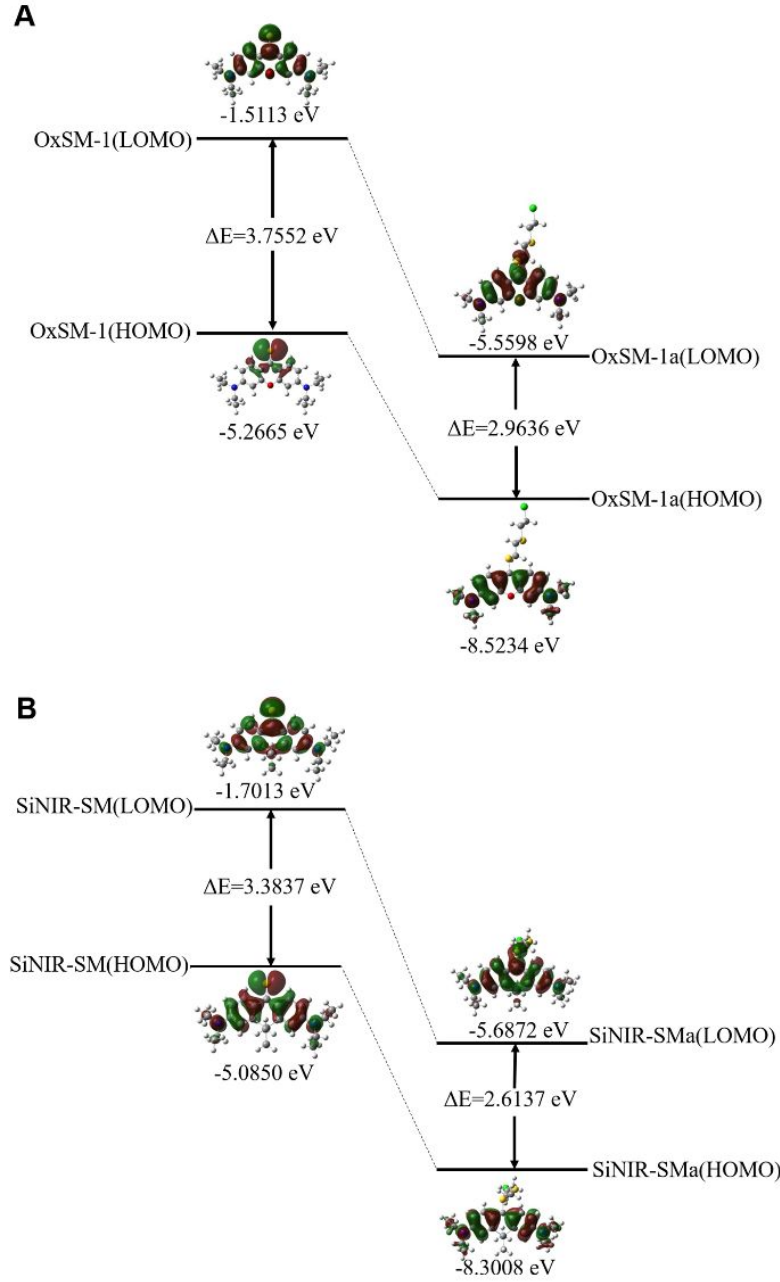

Figure S4. (A) Plots of the HOMO and LUMO of the ground state for OxSM-1 and OxSM-1a. (B) Plots of the HOMO and LUMO of the ground state for SiNIR-SM and SiNIR-SMa. 


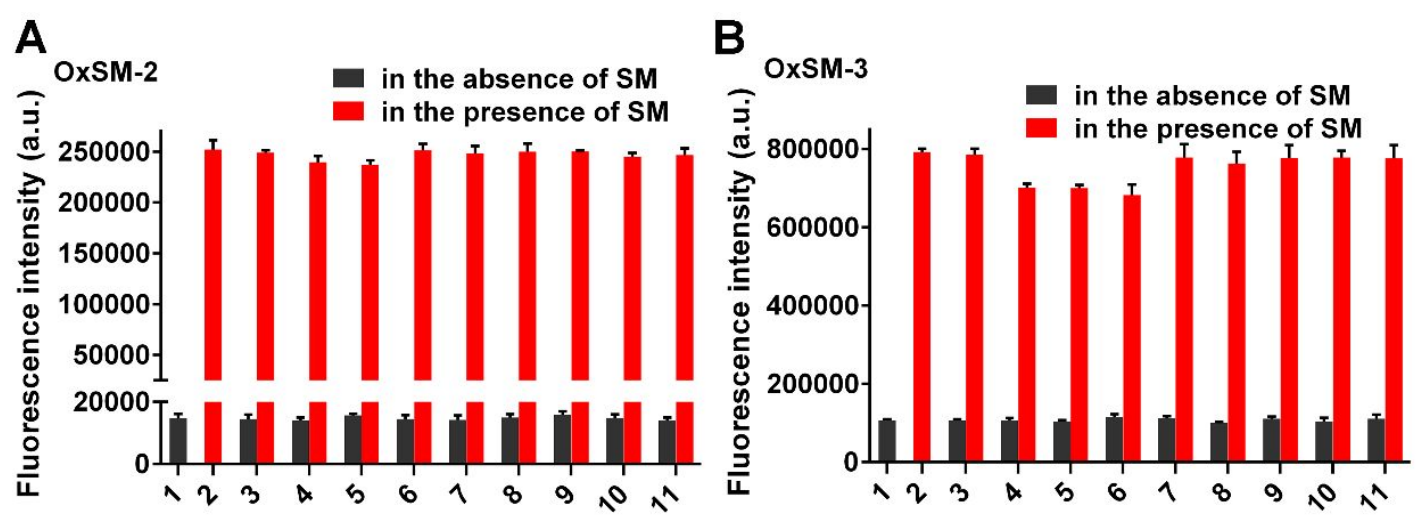

Figure S5. The selectivity of (A) OxSM-2 and (B) OxSM-3 for sulfur mustard. 1. Blank;

2. Sulfur mustard $(200 \mu \mathrm{M}) ; 3$. DCP $(200 \mu \mathrm{M}) ; 4$. $\mathrm{Na}_{2} \mathrm{~S}(200 \mu \mathrm{M}) ;$ 5. Glutathione (200

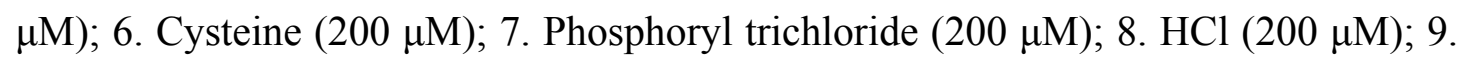
Iodoethane $(200 \mu \mathrm{M}) ; 10$. Ethyl iodide $(200 \mu \mathrm{M}) ; 11 . \mathrm{KCN}(200 \mu \mathrm{M})$. The excitation wavelength was $550 \mathrm{~nm}$. Data are presented as the mean $\pm \operatorname{SD}(\mathrm{n}=3)$. 

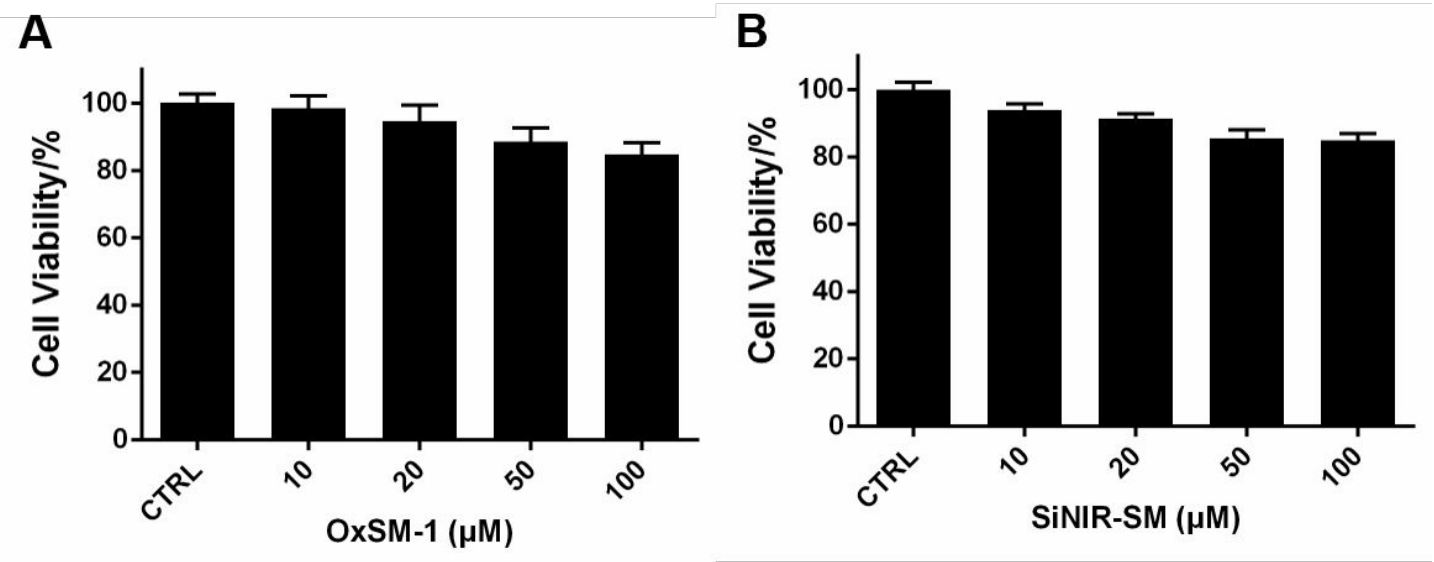

Figure S6. Untreated or OxSM-1/SiNIR-SM-treated HaCaT cells were further cultured for $24 \mathrm{~h}$. Cell viability was assessed using the CCK8 assay. (A) The inhibitory of OxSM-1 on cell growth in HaCaT cells treated for 24 h. (B) The inhibitory of SiNIR$\mathrm{SM}$ on cell growth in $\mathrm{HaCaT}$ cells treated for $24 \mathrm{~h}$. Data are presented as the mean \pm $\operatorname{SD}(n=3)$ 

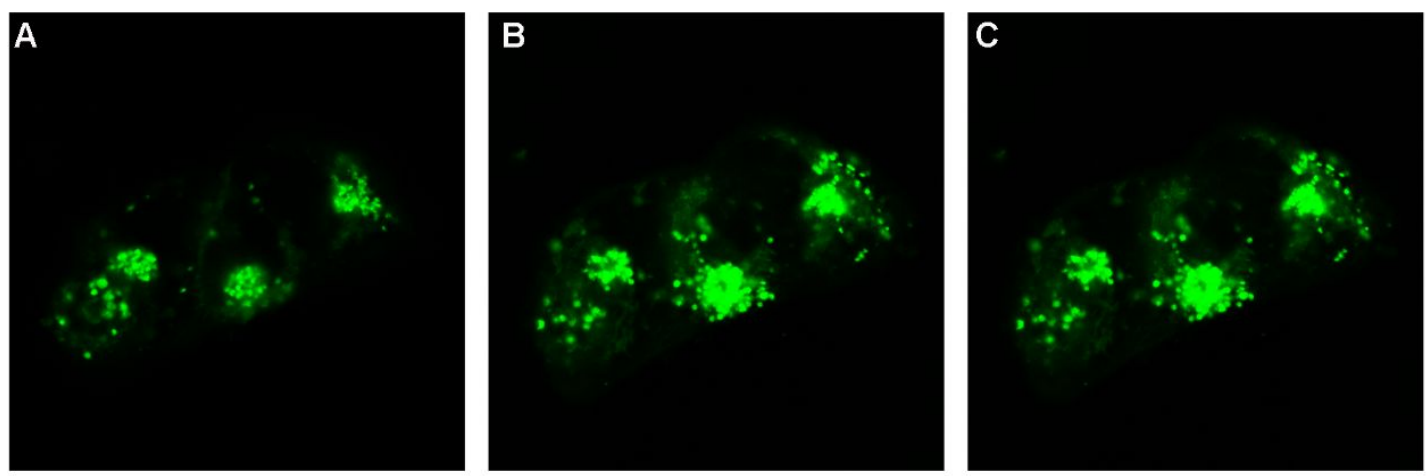

Figure S7. Time-dependent fluorescence imaging of OxSM-1 in living cells.

Fluorescent images of OxSM-1 were recorded at different time points: (A) 20 min, (B)

$25 \mathrm{~min}$, and (C) $30 \mathrm{~min}$. 


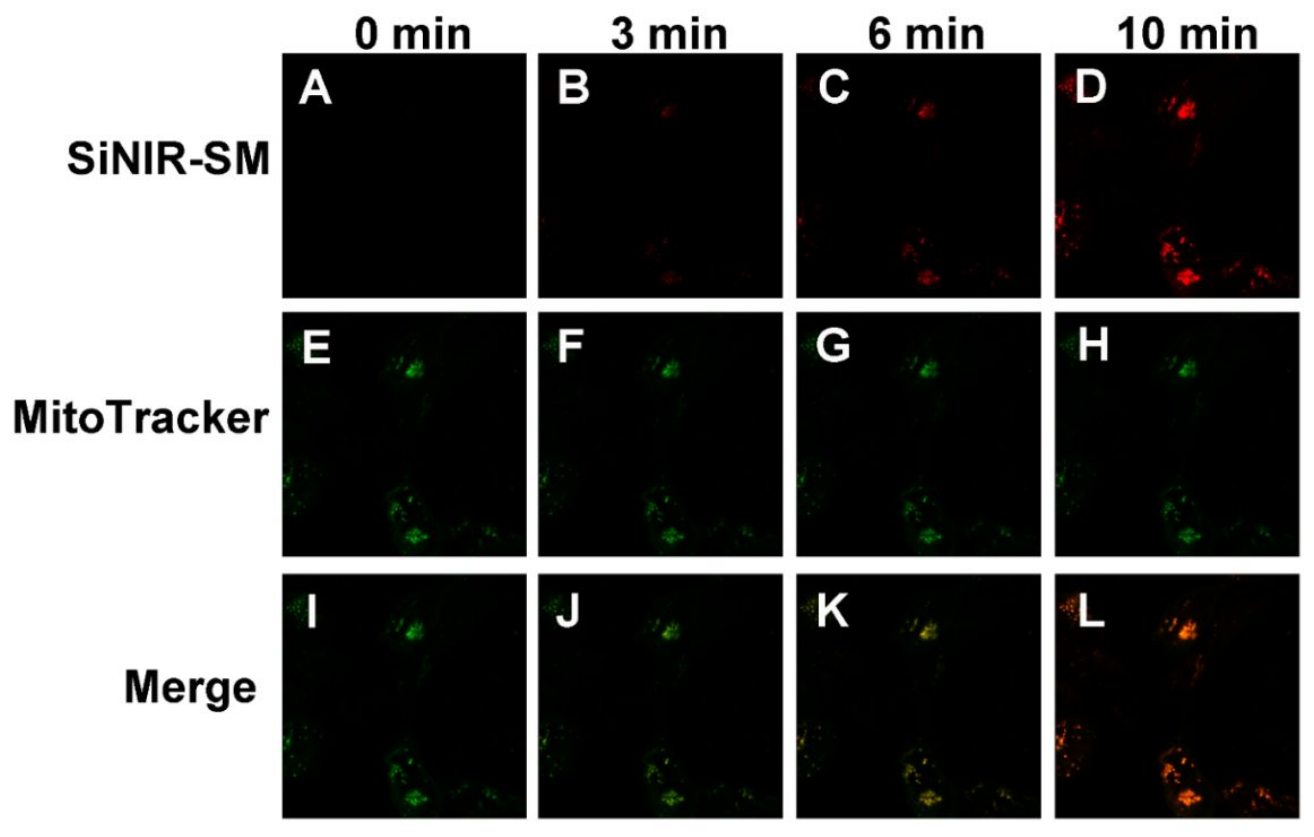

Figure S8. Confocal fluorescence imaging of HaCaT cells costained with SiNIR-SM $(10 \mu \mathrm{M})$ and MitoTracker Green $(5 \mu \mathrm{M})$. HaCaT cells were treated with SiNIR-SM (10 $\mu \mathrm{M})$ and MitoTracker Green $(5 \mu \mathrm{M})$ and then incubated with sulfur mustard $(20 \mu \mathrm{M})$. (A-D) The red channel is for SiNIR-SM under $633 \mathrm{~nm}$ excitation. (E-H) The green channel is for MitoTracker Green under $490 \mathrm{~nm}$ excitation. (I-L) Merge of the images of SiNIR-SM and MitoTracker Green. 


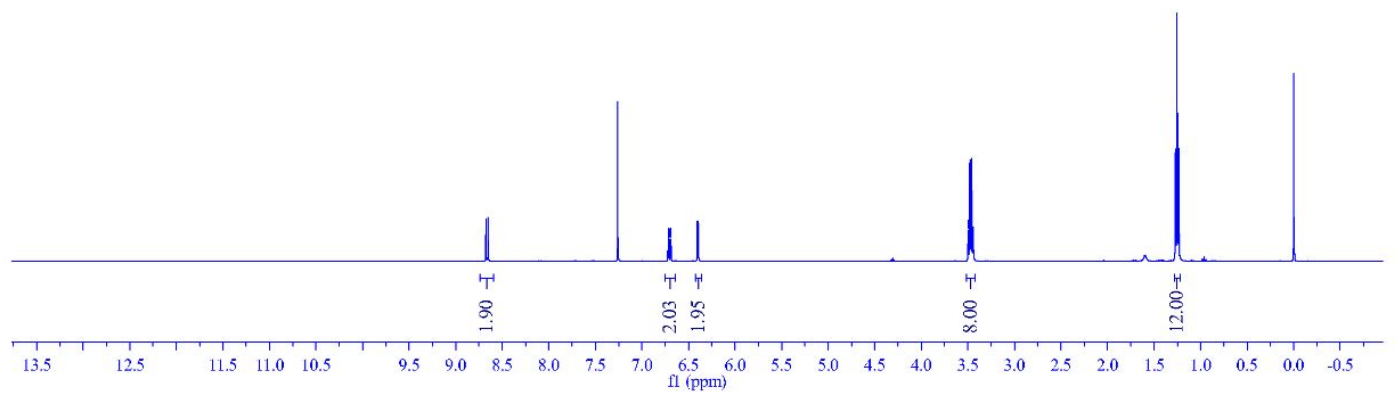

Figure S9. ${ }^{1} \mathrm{H}$ NMR for $\mathrm{OxSM}-1$ in $\mathrm{CDCl}_{3}(\mathrm{ppm})$.

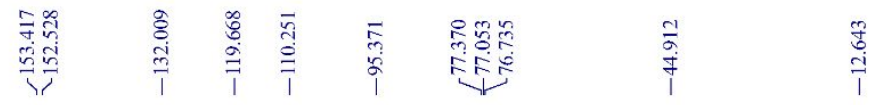

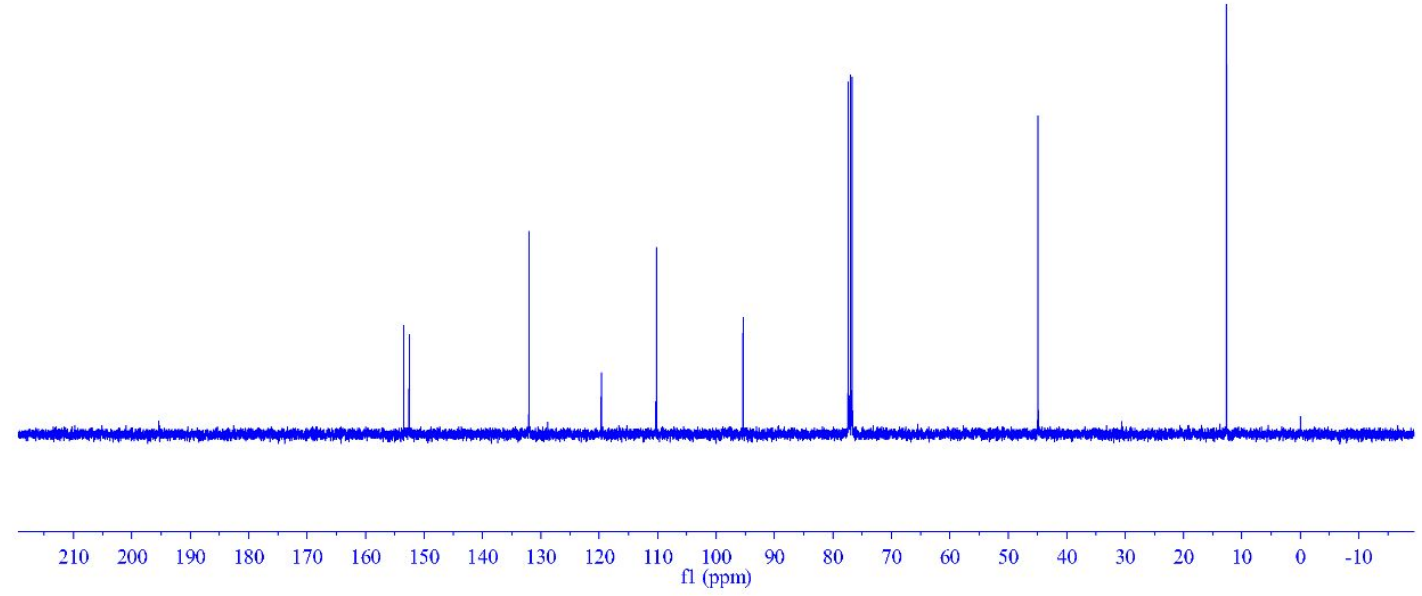

Figure S10. ${ }^{13} \mathrm{C}$ NMR for $\mathrm{OxSM}-1$ in $\mathrm{CDCl}_{3}$ (ppm). 


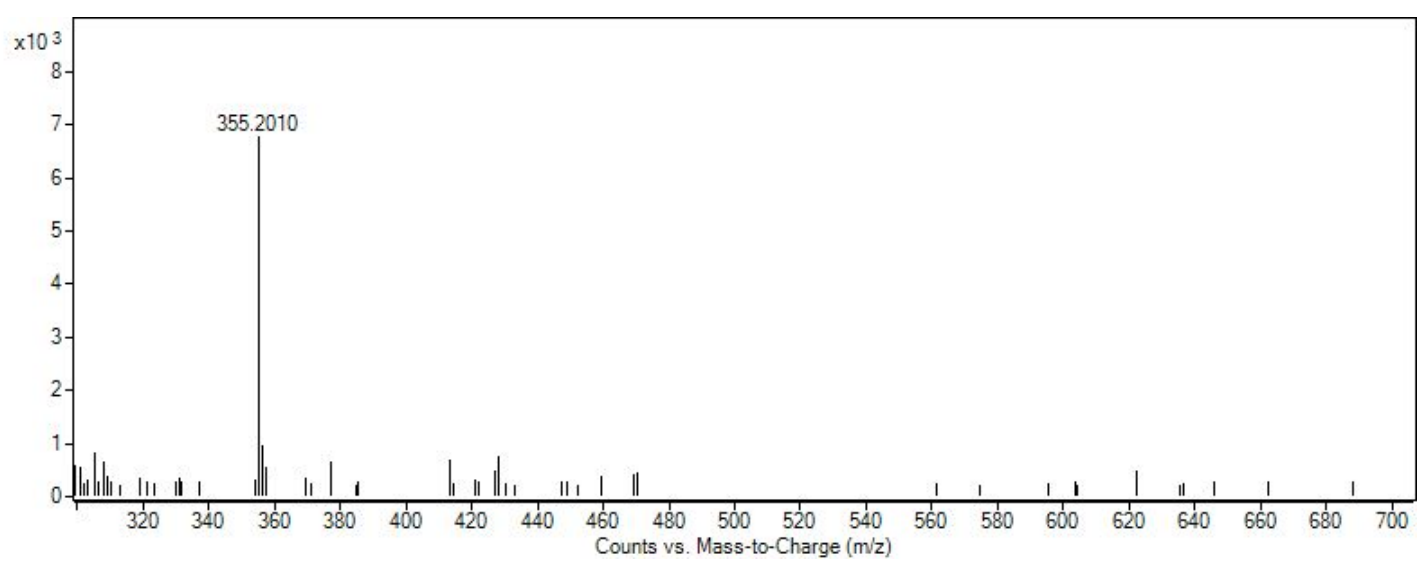

Figure S11. HRMS for OxSM-1 in MeCN.

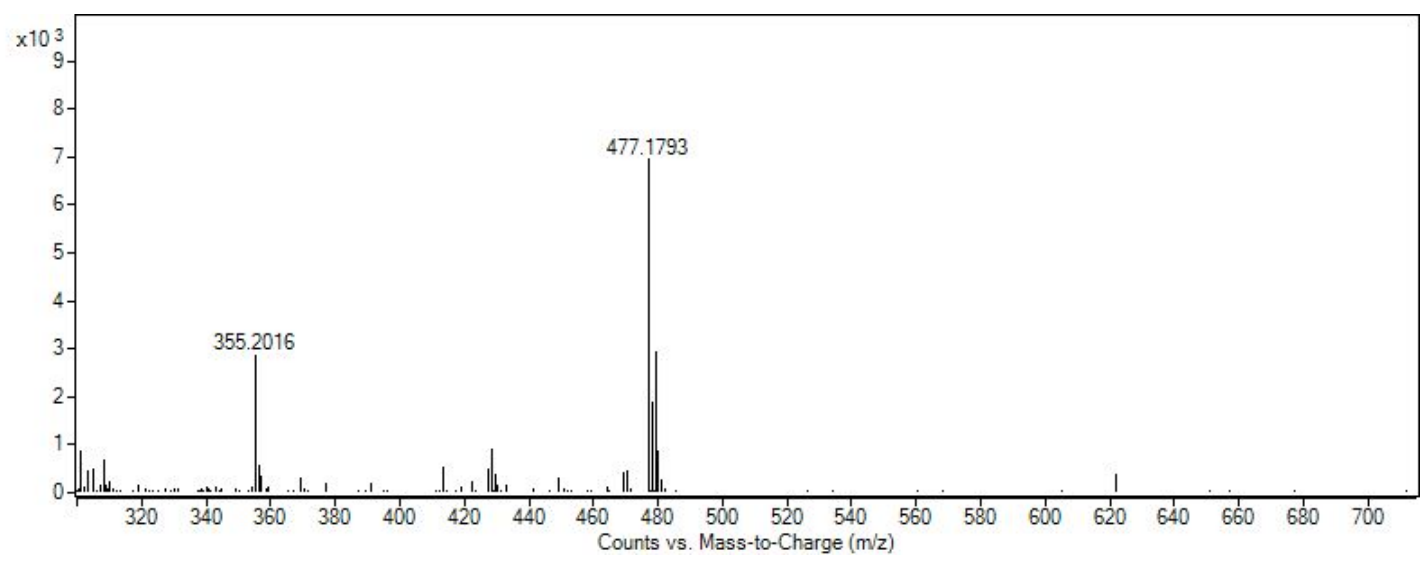

Figure S12. HRMS for the reaction solution between OxSM-1 and sulfur mustard in $\mathrm{MeCN}$. 


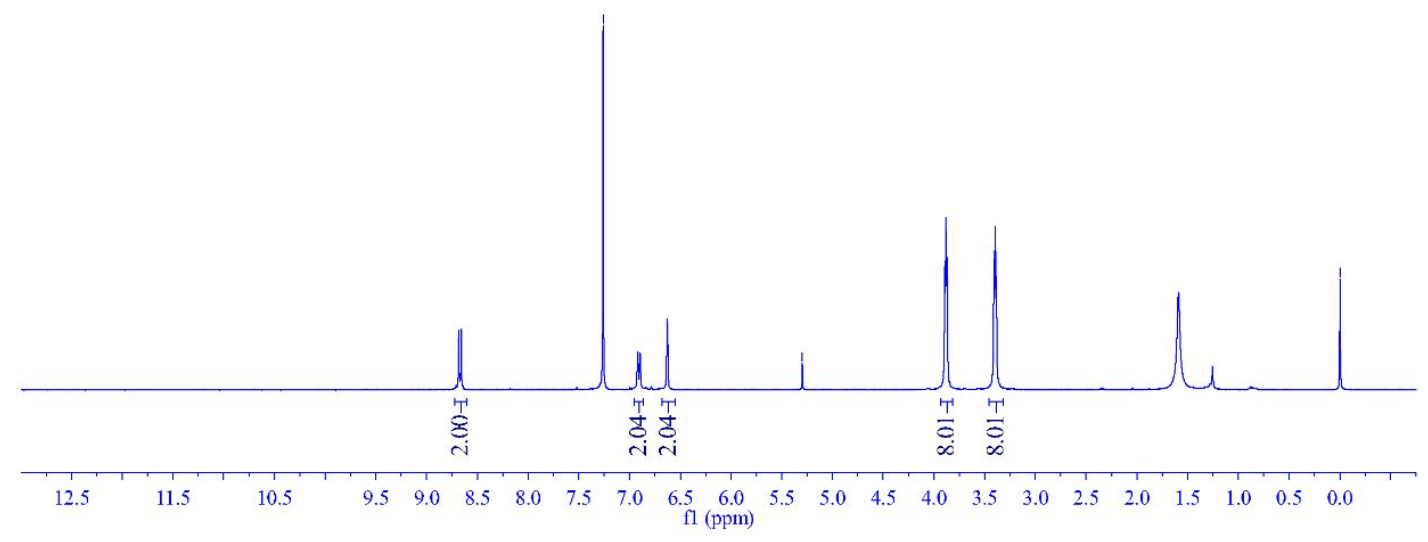

Figure S13. ${ }^{1} \mathrm{H}$ NMR for $\mathrm{OxSM}-2$ in $\mathrm{CDCl}_{3}$ (ppm).

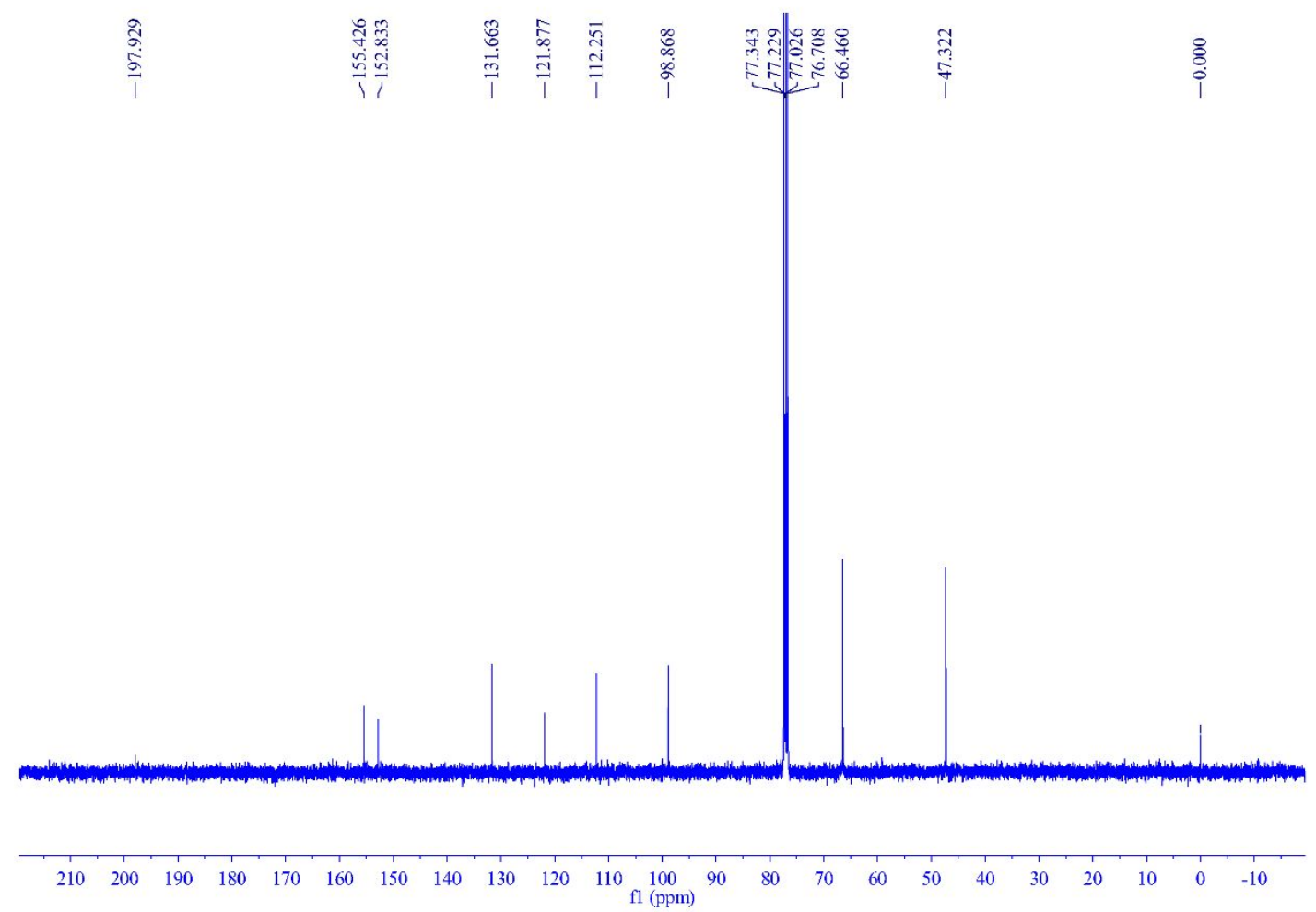

Figure S14. ${ }^{13} \mathrm{C}$ NMR for $\mathrm{OxSM}-2$ in $\mathrm{CDCl}_{3}(\mathrm{ppm})$. 


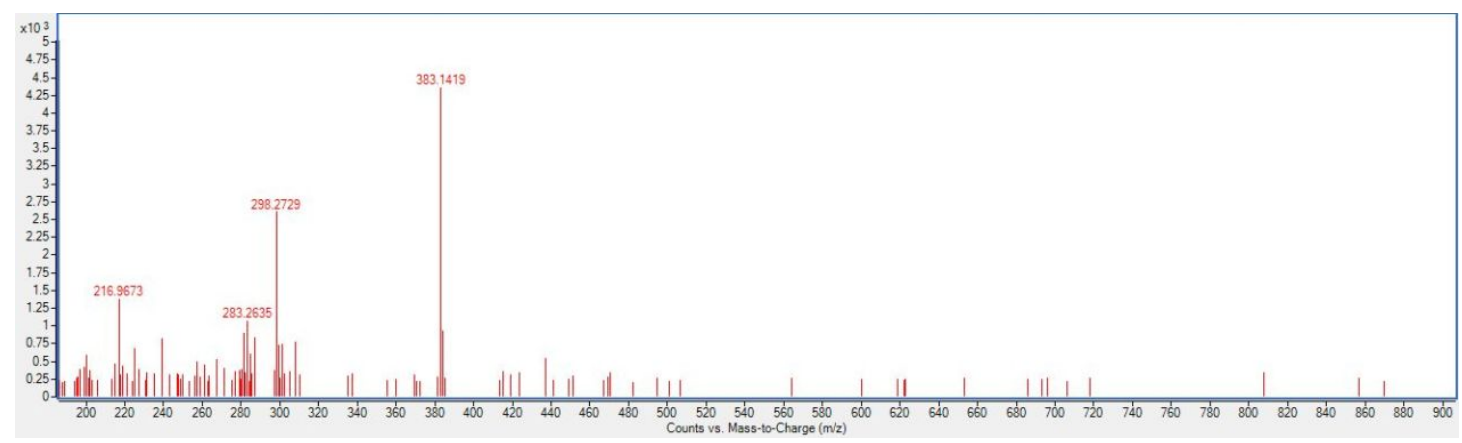

Figure S15. HRMS for OxSM-2 in MeCN.

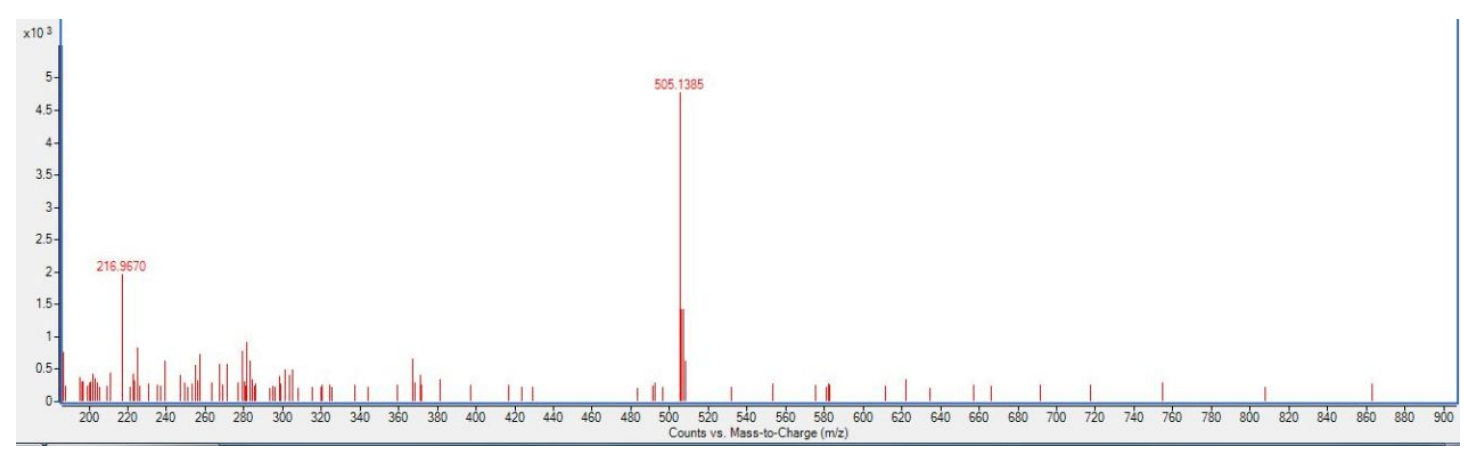

Figure S16. HRMS for the reaction solution between OxSM-2 and sulfur mustard in $\mathrm{MeCN}$.
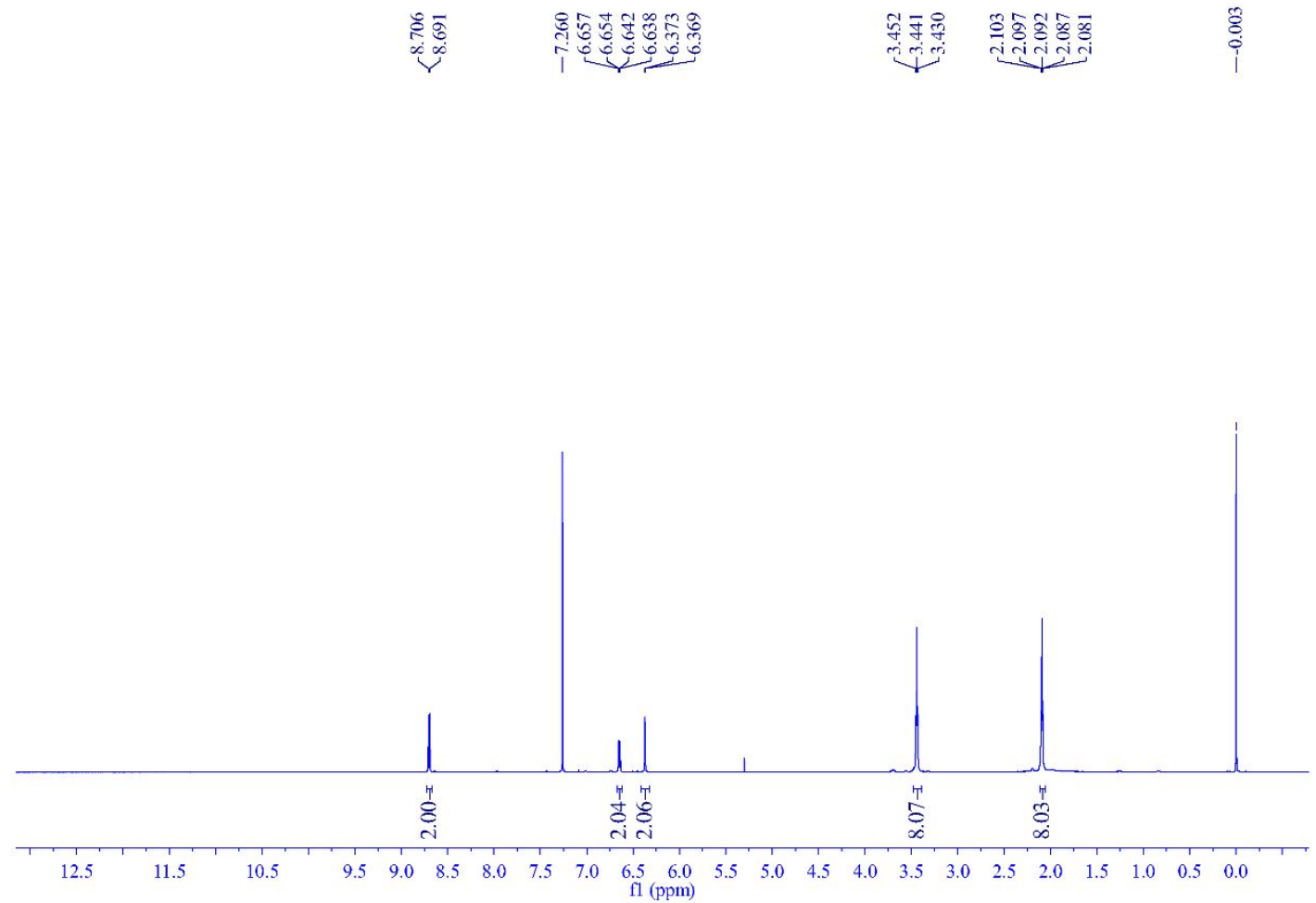

Figure S17. ${ }^{1} \mathrm{H}$ NMR for $\mathrm{OxSM}-3$ in $\mathrm{CDCl}_{3}(\mathrm{ppm})$. 


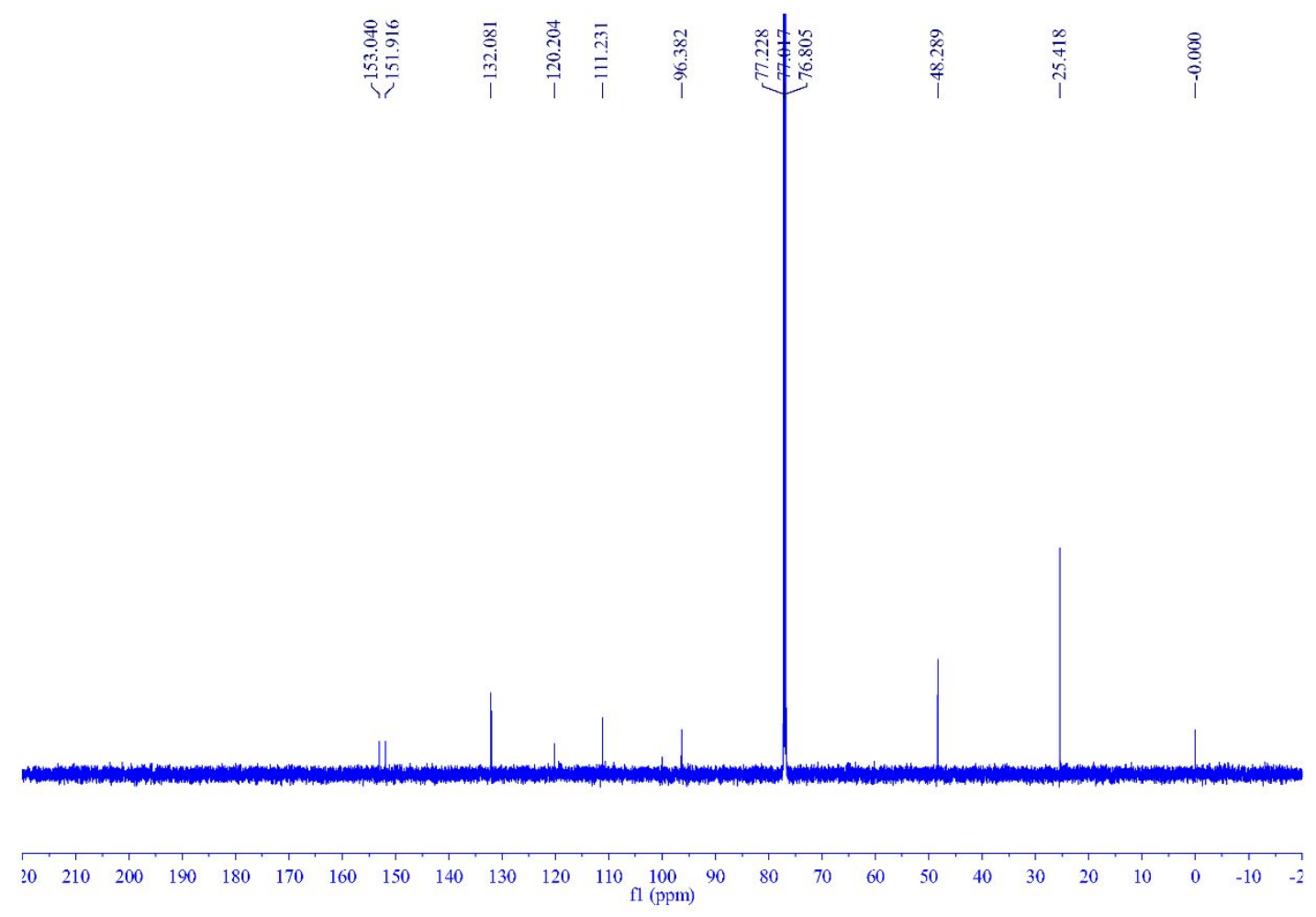

Figure S18. ${ }^{13} \mathrm{C}$ NMR for $\mathrm{OxSM}-3$ in $\mathrm{CDCl}_{3}(\mathrm{ppm})$.

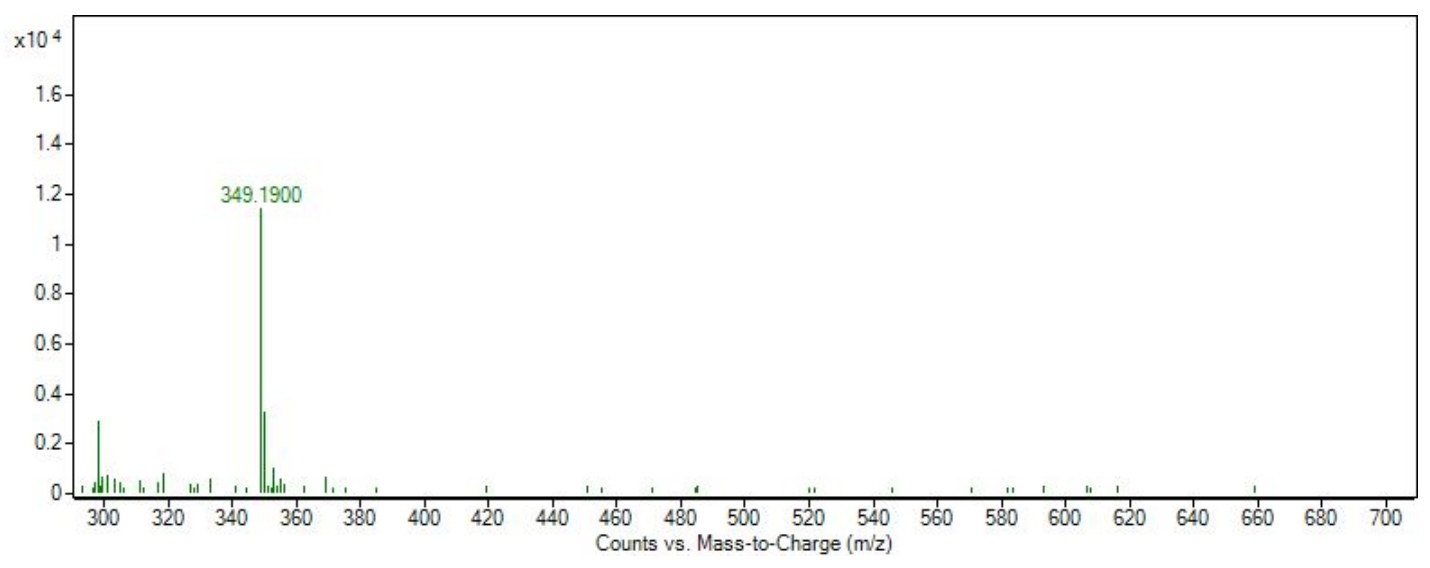

Figure S19. HRMS for OxSM-3 in MeCN.

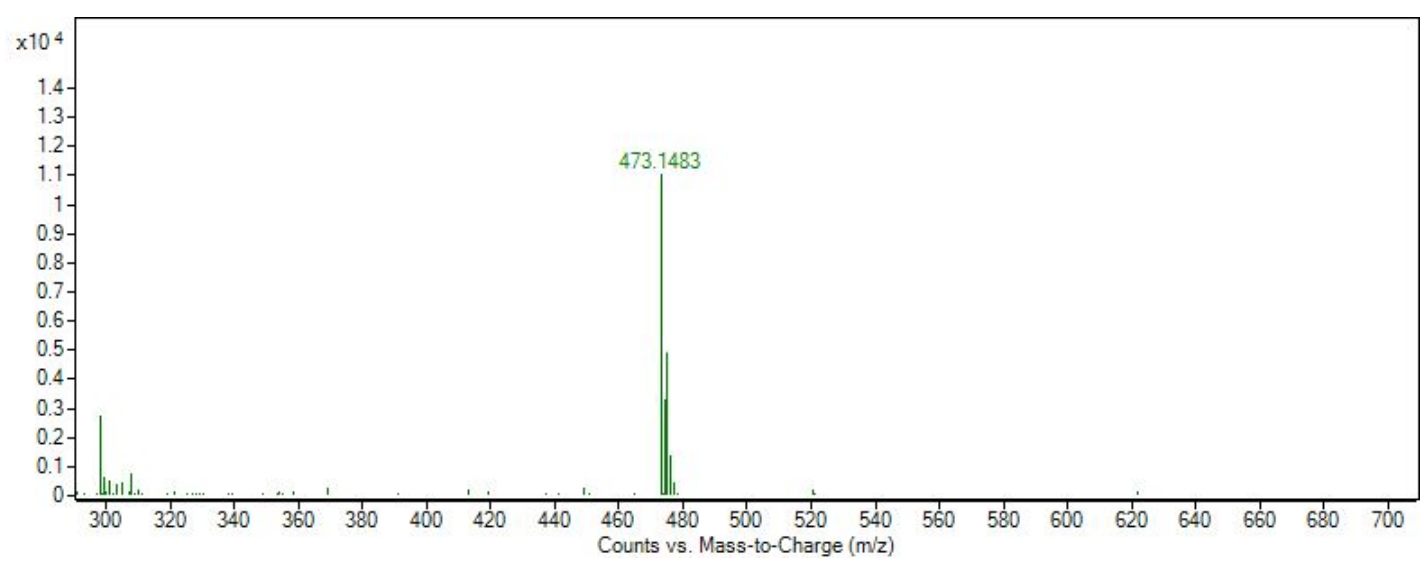

Figure S20. HRMS for the reaction solution between OxSM-3 and sulfur mustard in 
$\mathrm{MeCN}$.

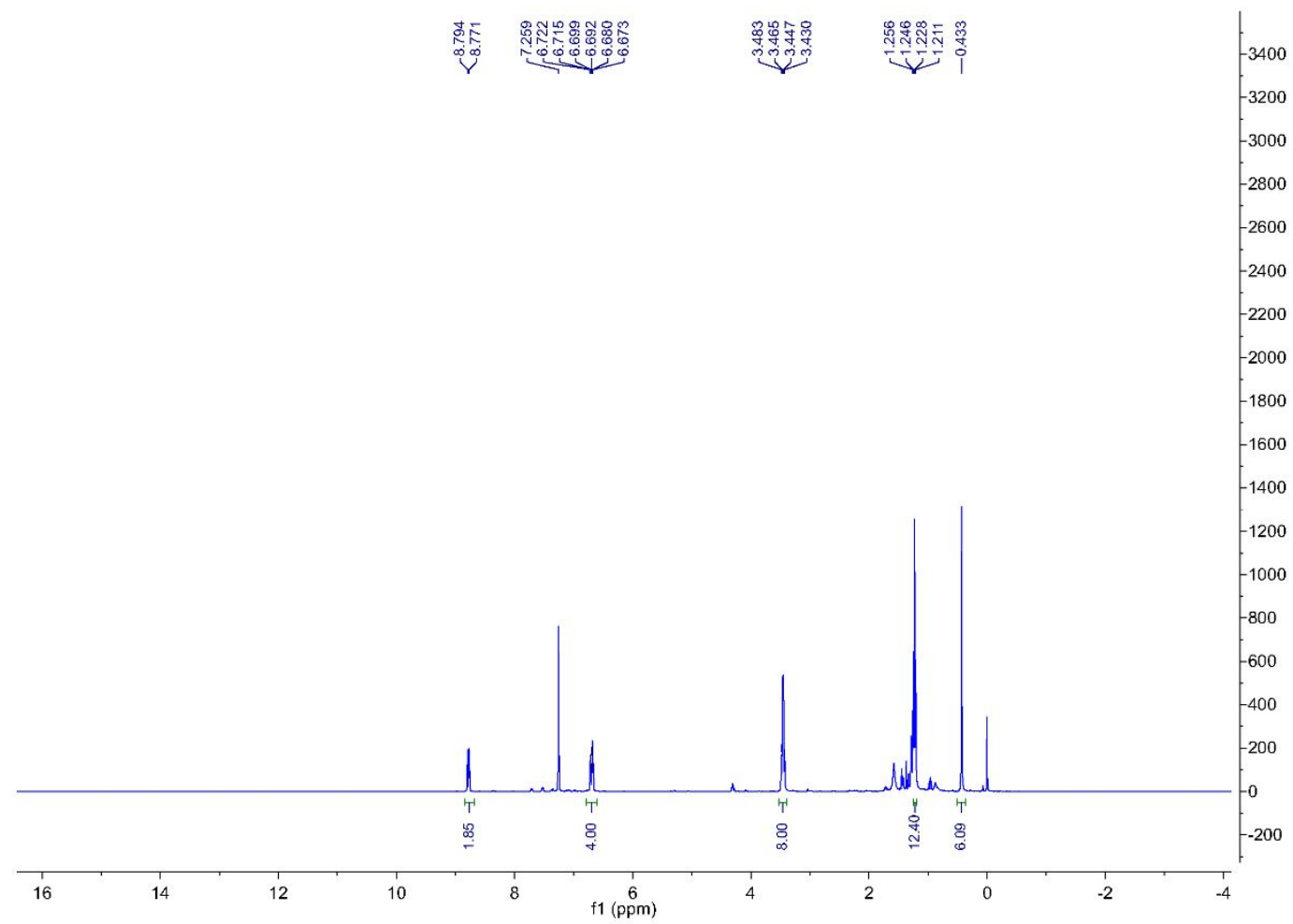

Figure S21. ${ }^{1} \mathrm{H}$ NMR for SiNIR-SM in $\mathrm{CDCl}_{3}(\mathrm{ppm})$.

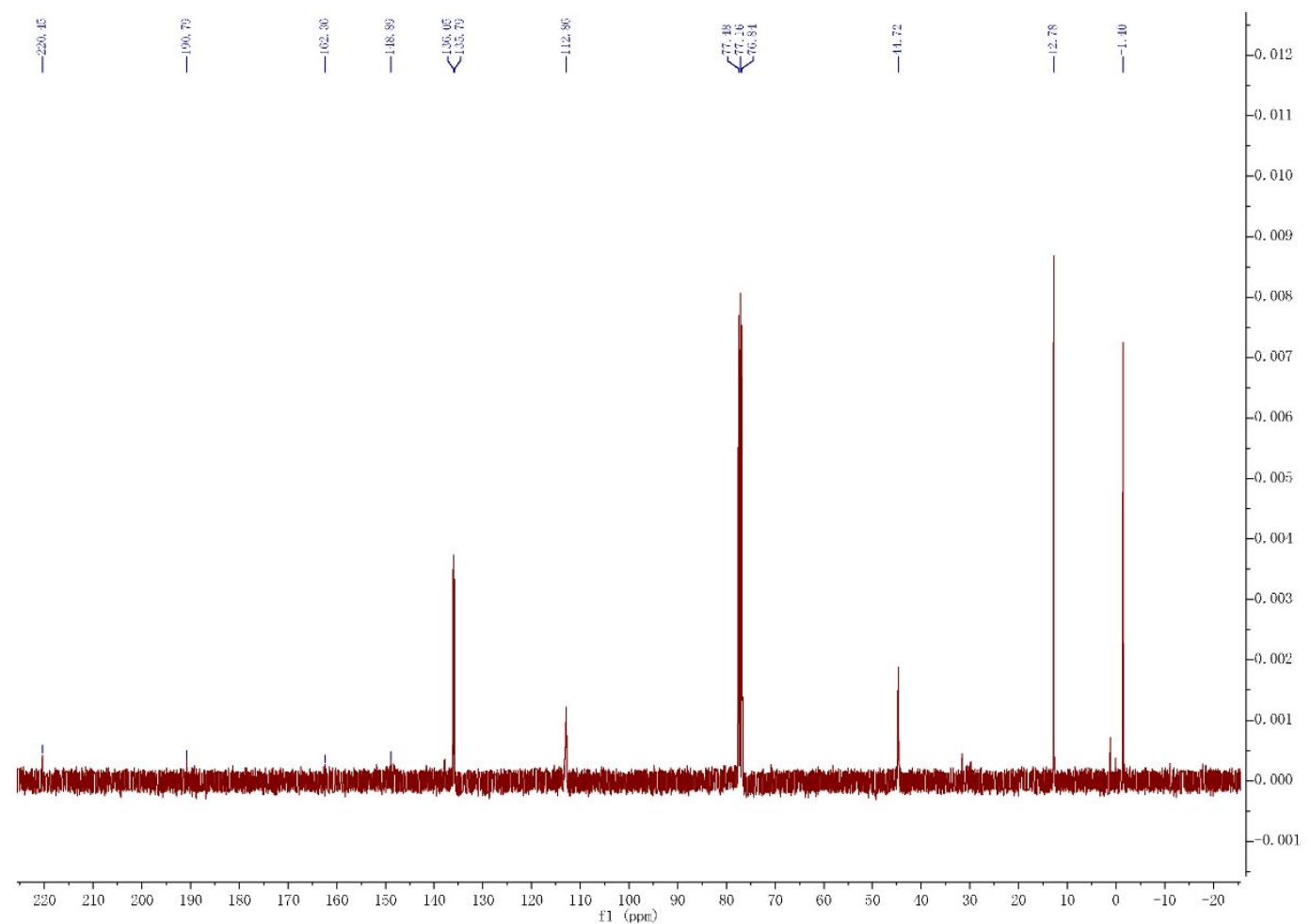

Figure S22. ${ }^{13} \mathrm{C}$ NMR for SiNIR-SM in $\mathrm{CDCl}_{3}(\mathrm{ppm})$. 


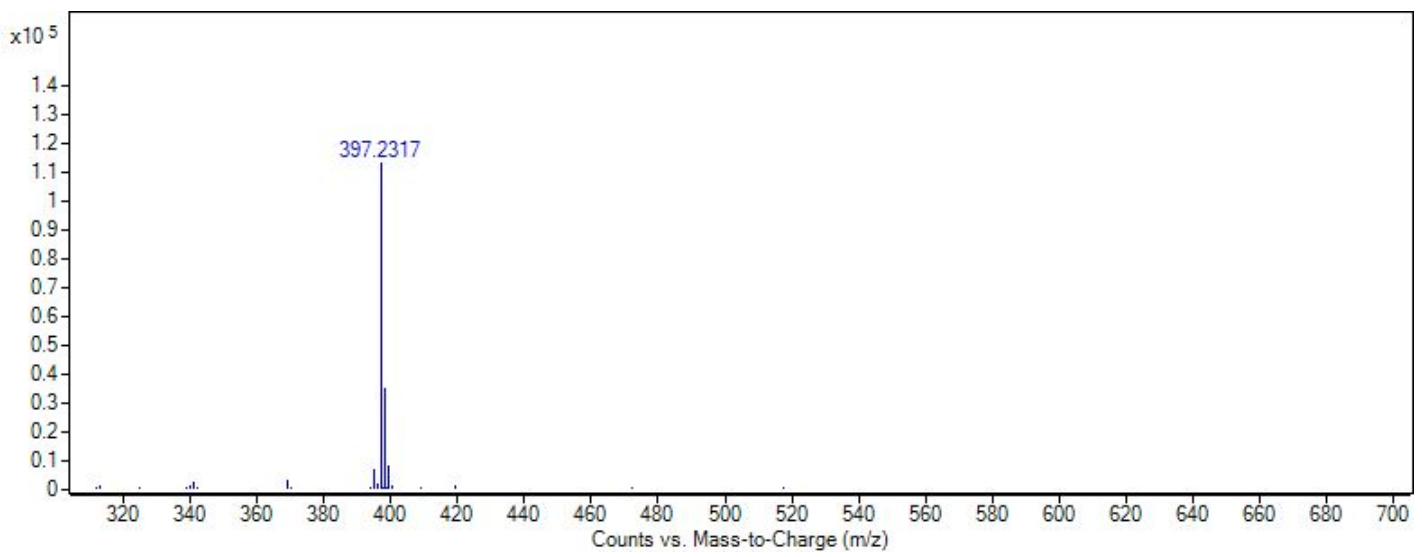

Figure S23. HRMS for SiNIR-SM in MeCN.

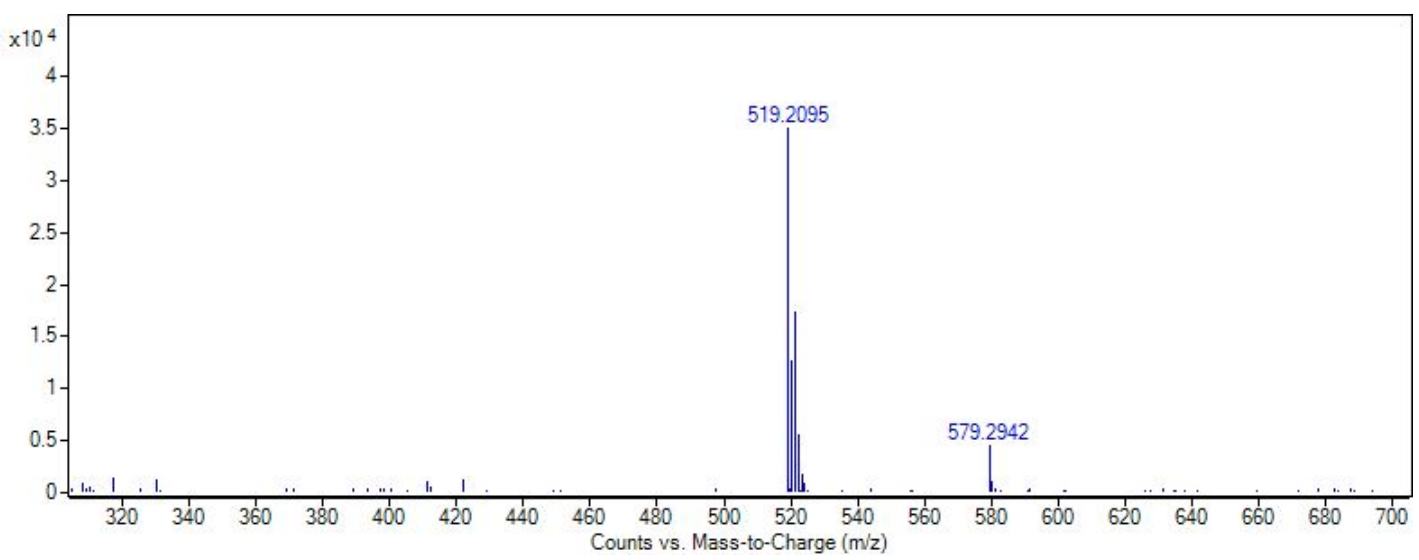

Figure S24. HRMS for the reaction solution between SiNIR-SM and sulfur mustard in $\mathrm{MeCN}$. 
XYZ Coordinates for compound OxSM-1, OxSM-1a, SiNIR-SM, and SiNIRSMa

\section{OXSM-1}

\begin{tabular}{llll} 
C & 3.65072700 & 1.19229400 & -0.12658100 \\
C & 3.58918900 & -0.22173000 & 0.01727800 \\
C & 2.31296400 & -0.80543200 & 0.07352900 \\
C & 1.17339800 & -0.01631700 & -0.00247100 \\
C & 1.21821000 & 1.38066000 & -0.14559400 \\
C & 2.50594700 & 1.94670000 & -0.20469600 \\
O & -0.00007800 & -0.69760800 & 0.06322500 \\
C & -1.17352800 & -0.01628400 & -0.00255300 \\
C & -1.21829100 & 1.38069300 & -0.14570300 \\
C & -0.00002600 & 2.16442300 & -0.22443700 \\
C & -2.31312200 & -0.80535900 & 0.07339600 \\
C & -3.58932900 & -0.22164000 & 0.01698600 \\
C & -3.65081600 & 1.19239600 & -0.12685100 \\
C & -2.50600500 & 1.94676800 & -0.20488700 \\
N & 4.72808900 & -0.97929200 & 0.10115400 \\
N & -4.72817100 & -0.97931300 & 0.10080200 \\
C & 4.67605100 & -2.40306500 & 0.37472200 \\
C & 6.04909600 & -0.40286200 & -0.07508700 \\
\hline & & & \\
\hline & & & \\
\hline
\end{tabular}




\begin{tabular}{|c|c|c|c|}
\hline$C$ & -6.04930000 & -0.40308300 & -0.07514500 \\
\hline$C$ & -4.67589000 & -2.40297100 & 0.37490800 \\
\hline$S$ & 0.00000600 & 3.82494800 & -0.39303700 \\
\hline$C$ & -4.52317500 & -3.26202700 & -0.87650600 \\
\hline$C$ & -6.64964400 & 0.15260100 & 1.21228100 \\
\hline$C$ & 6.64973100 & 0.15268700 & 1.21226300 \\
\hline$C$ & 4.52372900 & -3.26170900 & -0.87702700 \\
\hline $\mathrm{H}$ & 4.60810000 & 1.69888600 & -0.15633600 \\
\hline $\mathrm{H}$ & 2.16865900 & -1.87548200 & 0.15639100 \\
\hline $\mathrm{H}$ & 2.56564700 & 3.02630000 & -0.30797300 \\
\hline $\mathrm{H}$ & -2.16887400 & -1.87541300 & 0.15633300 \\
\hline $\mathrm{H}$ & -4.60814800 & 1.69905300 & -0.15661800 \\
\hline $\mathrm{H}$ & -2.56566500 & 3.02637200 & -0.30814300 \\
\hline $\mathrm{H}$ & 5.60191300 & -2.67059600 & 0.89776400 \\
\hline $\mathrm{H}$ & 3.86595700 & -2.60462700 & 1.08420700 \\
\hline $\mathrm{H}$ & 6.69711600 & -1.19032600 & -0.47771400 \\
\hline $\mathrm{H}$ & 6.00838200 & 0.36996400 & -0.84975300 \\
\hline $\mathrm{H}$ & -6.00891800 & 0.36961700 & -0.84993800 \\
\hline $\mathrm{H}$ & -6.69732200 & -1.19069000 & -0.47750000 \\
\hline $\mathrm{H}$ & -3.86587800 & -2.60410500 & 1.08461500 \\
\hline $\mathrm{H}$ & -5.60180000 & -2.67052500 & 0.89785200 \\
\hline $\mathrm{H}$ & -4.50176900 & -4.32569300 & -0.61426700 \\
\hline
\end{tabular}




\begin{tabular}{llll}
$\mathrm{H}$ & -5.35988400 & -3.09968400 & -1.56484900 \\
$\mathrm{H}$ & -3.59945200 & -3.02054800 & -1.41162500 \\
$\mathrm{H}$ & -7.65136900 & 0.55675400 & 1.02859800 \\
$\mathrm{H}$ & -6.73440100 & -0.63153900 & 1.97269500 \\
$\mathrm{H}$ & -6.02581700 & 0.95153300 & 1.62488800 \\
$\mathrm{H}$ & 7.65133800 & 0.55703100 & 1.02835600 \\
$\mathrm{H}$ & 6.02591300 & 0.95143700 & 1.62522700 \\
$\mathrm{H}$ & 6.73483300 & -0.63159100 & 1.97249700 \\
$\mathrm{H}$ & 4.50253000 & -4.32547800 & -0.61519300 \\
$\mathrm{H}$ & & & \\
$\mathrm{H}$ & 3.60001300 & -3.02023300 & -1.41216300 \\
$\mathrm{H}$ & & & \\
\hline & 5.36048700 & -3.09892700 & -1.56520600
\end{tabular}

\section{OXSM-1a}

$\begin{array}{llll}\text { C } & -2.53870500 & -3.26241300 & -0.56082100 \\ \text { C } & -3.73079800 & -2.66404800 & -0.02984800 \\ \text { C } & -3.70229100 & -1.27128200 & 0.21684100 \\ \text { C } & -2.57251000 & -0.53967200 & -0.06689500 \\ \text { C } & -1.38693900 & -1.11578300 & -0.60594400 \\ \text { C } & -1.42608800 & -2.52020100 & -0.82457800 \\ \text { O } & -2.63489300 & 0.78253000 & 0.20950200 \\ \text { C } & -1.60093800 & 1.60851800 & -0.06859800 \\ \text { C } & -0.39605900 & 1.10108300 & -0.62811900\end{array}$




\begin{tabular}{|c|c|c|c|}
\hline C & -0.28139200 & -0.28347300 & -0.86236300 \\
\hline C & -1.79466000 & 2.94032300 & 0.22082400 \\
\hline C & -0.77772500 & 3.88388000 & -0.05188300 \\
\hline C & 0.42413500 & 3.39528700 & -0.66705200 \\
\hline C & 0.59432200 & 2.07027100 & -0.94105600 \\
\hline $\mathrm{N}$ & -4.82428900 & -3.40634700 & 0.23361400 \\
\hline $\mathrm{N}$ & -0.93324000 & 5.19384300 & 0.22655700 \\
\hline$S$ & 1.20601700 & -0.98301600 & -1.52872200 \\
\hline $\mathrm{C}$ & 2.38164300 & -0.69719400 & -0.14606100 \\
\hline C & 3.73948400 & -1.23689000 & -0.56861000 \\
\hline$S$ & 4.91249700 & -0.93330100 & 0.78786500 \\
\hline$C$ & 6.37556700 & -1.75724100 & 0.07842500 \\
\hline C & 7.52633800 & -1.63200600 & 1.05861300 \\
\hline C & -4.91390600 & -4.82371100 & -0.11347900 \\
\hline$C$ & -6.00451500 & -2.84010600 & 0.88141700 \\
\hline$C$ & -4.39058900 & -5.74327600 & 0.98206300 \\
\hline C & -6.99088300 & -2.22369800 & -0.10279100 \\
\hline C & 0.14565300 & 6.16561300 & 0.05947800 \\
\hline C & -2.19528900 & 5.73202600 & 0.72650300 \\
\hline$C$ & 0.18176600 & 6.79208500 & -1.32836200 \\
\hline$C$ & -2.31685600 & 5.66645800 & 2.24392600 \\
\hline $\mathrm{Cl}$ & 8.97985300 & -2.43329800 & 0.39655000 \\
\hline
\end{tabular}




\begin{tabular}{|c|c|c|c|}
\hline $\mathrm{H}$ & -2.49978400 & -4.33062600 & -0.73199700 \\
\hline $\mathrm{H}$ & -4.55821100 & -0.73786500 & 0.60888700 \\
\hline $\mathrm{H}$ & -0.53500900 & -3.00489600 & -1.20895100 \\
\hline $\mathrm{H}$ & -2.73764800 & 3.22281600 & 0.67029500 \\
\hline $\mathrm{H}$ & 1.20119000 & 4.08922700 & -0.96166700 \\
\hline $\mathrm{H}$ & 1.49333000 & 1.74164000 & -1.45256800 \\
\hline $\mathrm{H}$ & 2.44286100 & 0.37075500 & 0.07897300 \\
\hline $\mathrm{H}$ & 2.01483600 & -1.22398500 & 0.73886500 \\
\hline $\mathrm{H}$ & 3.67850000 & -2.31272300 & -0.76754400 \\
\hline $\mathrm{H}$ & 4.08651600 & -0.73583600 & -1.47946700 \\
\hline $\mathrm{H}$ & 6.15166700 & -2.81339300 & -0.10262600 \\
\hline $\mathrm{H}$ & 6.64143300 & -1.28502400 & -0.87270500 \\
\hline $\mathrm{H}$ & 7.78474000 & -0.58665900 & 1.24060300 \\
\hline $\mathrm{H}$ & 7.29425600 & -2.11289600 & 2.01123800 \\
\hline $\mathrm{H}$ & -5.97073900 & -5.03245900 & -0.30859000 \\
\hline $\mathrm{H}$ & -4.39743000 & -4.99814400 & -1.06150400 \\
\hline $\mathrm{H}$ & -6.48308300 & -3.65403600 & 1.43556100 \\
\hline $\mathrm{H}$ & -5.68612800 & -2.11254500 & 1.63404100 \\
\hline $\mathrm{H}$ & -4.51404000 & -6.78955300 & 0.68542300 \\
\hline $\mathrm{H}$ & -3.32896500 & -5.56619800 & 1.18132600 \\
\hline $\mathrm{H}$ & -4.93799500 & -5.59206700 & 1.91816800 \\
\hline $\mathrm{H}$ & -7.86387700 & -1.83771300 & 0.43282000 \\
\hline
\end{tabular}




\begin{tabular}{|c|c|c|c|}
\hline $\mathrm{H}$ & -6.53817400 & -1.39867400 & -0.66147300 \\
\hline $\mathrm{H}$ & -7.34163800 & -2.96697400 & -0.82610400 \\
\hline $\mathrm{H}$ & -0.00875600 & 6.93963000 & 0.81849400 \\
\hline $\mathrm{H}$ & 1.09956400 & 5.69267000 & 0.30877200 \\
\hline $\mathrm{H}$ & -2.25258900 & 6.77167500 & 0.38827200 \\
\hline $\mathrm{H}$ & -3.02503800 & 5.21265400 & 0.23750700 \\
\hline $\mathrm{H}$ & 0.98159000 & 7.53720800 & -1.38357700 \\
\hline $\mathrm{H}$ & 0.35885900 & 6.04085000 & -2.10453900 \\
\hline $\mathrm{H}$ & -0.76299200 & 7.29543100 & -1.55826300 \\
\hline $\mathrm{H}$ & -3.26799500 & 6.10348100 & 2.56383400 \\
\hline $\mathrm{H}$ & -2.27377400 & 4.63474200 & 2.60643200 \\
\hline $\mathrm{H}$ & -1.50994100 & 6.22660800 & 2.72743100 \\
\hline
\end{tabular}

\section{SiNIR-SM}

\begin{tabular}{llll} 
C & -3.66434800 & 1.49568700 & -0.31713800 \\
C & -3.85539600 & 0.10146300 & -0.18887600 \\
C & -2.70867800 & -0.66034600 & 0.12142100 \\
C & -1.44885900 & -0.09101100 & 0.28337600 \\
C & -1.27426700 & 1.30873300 & 0.16652200 \\
C & -2.42315900 & 2.06586400 & -0.13233500 \\
Si & & & \\
C & 0.00150400 & -1.17303600 & 0.74436100 \\
& & & \\
\hline
\end{tabular}




\begin{tabular}{|c|c|c|c|}
\hline$C$ & 1.29978600 & 1.29025100 & 0.13822800 \\
\hline C & 0.01965300 & 2.00332400 & 0.33304600 \\
\hline$C$ & 2.70630900 & -0.69835000 & 0.07031800 \\
\hline C & 3.85694600 & 0.04670900 & -0.26601100 \\
\hline$C$ & 3.68132900 & 1.44268000 & -0.39665400 \\
\hline$C$ & 2.45117400 & 2.02988000 & -0.19207300 \\
\hline $\mathrm{N}$ & -5.08783700 & -0.47827300 & -0.36214800 \\
\hline $\mathrm{N}$ & 5.07785000 & -0.55035300 & -0.46134400 \\
\hline$C$ & -5.26105400 & -1.91810700 & -0.37369000 \\
\hline$C$ & -6.28829200 & 0.31745100 & -0.53782800 \\
\hline$C$ & 6.23374900 & 0.20486400 & -0.90765000 \\
\hline$C$ & 5.28550300 & -1.96323000 & -0.20765800 \\
\hline$S$ & 0.03529700 & 3.62816000 & 0.71425100 \\
\hline$C$ & -0.01903900 & -2.79167000 & -0.22334800 \\
\hline$C$ & 0.01280000 & -1.53819700 & 2.59500700 \\
\hline$C$ & 4.95602900 & -2.85425100 & -1.40160200 \\
\hline$C$ & 7.01264800 & 0.85940600 & 0.22927700 \\
\hline $\mathrm{C}$ & -5.48517700 & -2.51897300 & 1.01087300 \\
\hline$C$ & -6.57760300 & 0.67616400 & -1.99212300 \\
\hline $\mathrm{H}$ & -4.49145600 & 2.14270300 & -0.58805800 \\
\hline $\mathrm{H}$ & -2.80845200 & -1.73359800 & 0.25431600 \\
\hline $\mathrm{H}$ & -2.31500600 & 3.14061100 & -0.23748200 \\
\hline
\end{tabular}




\begin{tabular}{|c|c|c|c|}
\hline $\mathrm{H}$ & 2.78488400 & -1.77715700 & 0.16664500 \\
\hline $\mathrm{H}$ & 4.51942300 & 2.08321700 & -0.64802600 \\
\hline $\mathrm{H}$ & 2.35786600 & 3.10678400 & -0.28893300 \\
\hline $\mathrm{H}$ & -6.12088800 & -2.14072300 & -1.01718400 \\
\hline $\mathrm{H}$ & -4.39760100 & -2.38267700 & -0.86240800 \\
\hline $\mathrm{H}$ & -7.12667800 & -0.25596100 & -0.12377000 \\
\hline $\mathrm{H}$ & -6.21608500 & 1.22138600 & 0.07648900 \\
\hline $\mathrm{H}$ & 6.88594100 & -0.48631200 & -1.45485600 \\
\hline $\mathrm{H}$ & 5.91675800 & 0.95430900 & -1.64095400 \\
\hline $\mathrm{H}$ & 6.33706100 & -2.09569600 & 0.07345300 \\
\hline $\mathrm{H}$ & 4.70470100 & -2.26415500 & 0.67144700 \\
\hline $\mathrm{H}$ & -0.03134800 & -2.60356200 & -1.30198100 \\
\hline $\mathrm{H}$ & 0.86084400 & -3.40533400 & 0.00356600 \\
\hline $\mathrm{H}$ & -0.90123600 & -3.39347400 & 0.02518000 \\
\hline $\mathrm{H}$ & -0.87596100 & -2.10819100 & 2.89014100 \\
\hline $\mathrm{H}$ & 0.89753500 & -2.12072700 & 2.87728200 \\
\hline $\mathrm{H}$ & 0.02352600 & -0.60704300 & 3.17115200 \\
\hline $\mathrm{H}$ & 5.14272800 & -3.90729000 & -1.16240700 \\
\hline $\mathrm{H}$ & 3.90701100 & -2.74757700 & -1.69519100 \\
\hline $\mathrm{H}$ & 5.57321300 & -2.58808300 & -2.26665000 \\
\hline $\mathrm{H}$ & 7.88115900 & 1.40304200 & -0.15912200 \\
\hline $\mathrm{H}$ & 6.38396100 & 1.56395900 & 0.78260600 \\
\hline
\end{tabular}




$\begin{array}{lrrr}H & 7.37306700 & 0.10551400 & 0.93778900 \\ H & -5.62136800 & -3.60433800 & 0.94510400 \\ H & -4.63544900 & -2.31638300 & 1.67032200 \\ H & -6.37914200 & -2.09321200 & 1.47954000 \\ H & -7.49945400 & 1.26343800 & -2.06979100 \\ H & -5.75919500 & 1.26058200 & -2.42384700 \\ H & -6.69930800 & -0.22740300 & -2.59975800\end{array}$

\section{SiNIR-SMa}

\begin{tabular}{|c|c|c|c|}
\hline C & -3.96889000 & -0.32190100 & -1.33073600 \\
\hline C & -4.36159700 & 0.46922700 & -0.21526300 \\
\hline C & -3.30608100 & 1.06871000 & 0.53675400 \\
\hline C & -1.98205500 & 0.97222600 & 0.17401800 \\
\hline C & -1.60354600 & 0.23471000 & -0.99730100 \\
\hline C & -2.65231200 & -0.44359800 & -1.68203100 \\
\hline C & 0.84296000 & 1.68574100 & 0.21939100 \\
\hline C & 0.83264800 & 1.00482000 & -1.04047700 \\
\hline C & -0.26449000 & 0.20333400 & -1.49758900 \\
\hline C & 1.94903700 & 2.40856900 & 0.61061500 \\
\hline C & 3.11636300 & 2.53875800 & -0.19866500 \\
\hline C & 3.05912400 & 1.93505000 & -1.48587300 \\
\hline C & 1.96828100 & 1.20540900 & -1.87436600 \\
\hline
\end{tabular}




\begin{tabular}{|c|c|c|c|}
\hline $\mathrm{N}$ & -5.65579600 & 0.62373300 & 0.12602400 \\
\hline $\mathrm{N}$ & 4.20181300 & 3.22167900 & 0.21799200 \\
\hline$S$ & 0.02719200 & -0.86260800 & -2.89616300 \\
\hline C & 1.42071400 & -1.90024000 & -2.32813900 \\
\hline C & 1.01949200 & -2.84564200 & -1.20925300 \\
\hline$S$ & 2.46344800 & -3.86351300 & -0.77139100 \\
\hline$C$ & 1.68509300 & -4.91434500 & 0.49741500 \\
\hline$C$ & 2.71485200 & -5.90222900 & 1.01060100 \\
\hline C & -6.74257300 & 0.09920300 & -0.69887600 \\
\hline$C$ & -6.06792700 & 1.33560000 & 1.33343800 \\
\hline$C$ & -7.12923600 & -1.32991400 & -0.34017700 \\
\hline$C$ & -6.19988000 & 2.83893000 & 1.12488900 \\
\hline$C$ & 5.43524700 & 3.26849500 & -0.56392300 \\
\hline$C$ & 4.22989200 & 3.95016600 & 1.48360700 \\
\hline$C$ & 5.47635800 & 4.42921500 & -1.54969500 \\
\hline$C$ & 4.63367300 & 3.07861700 & 2.66627900 \\
\hline $\mathrm{Cl}$ & 1.99329100 & -6.93024100 & 2.28339800 \\
\hline $\mathrm{H}$ & -4.70793700 & -0.86892300 & -1.90326600 \\
\hline $\mathrm{H}$ & -3.55881400 & 1.63767900 & 1.42550100 \\
\hline $\mathrm{H}$ & -2.41077600 & -1.07905700 & -2.52643800 \\
\hline $\mathrm{H}$ & 1.93170100 & 2.89442000 & 1.58086600 \\
\hline $\mathrm{H}$ & 3.86171700 & 2.08400400 & -2.19796100 \\
\hline
\end{tabular}




\begin{tabular}{|c|c|c|c|}
\hline $\mathrm{H}$ & 1.94842400 & 0.81664100 & -2.88764000 \\
\hline $\mathrm{H}$ & 1.70929700 & -2.45960200 & -3.22469100 \\
\hline $\mathrm{H}$ & 2.26766200 & -1.27547200 & -2.03447800 \\
\hline $\mathrm{H}$ & 0.68910900 & -2.27694000 & -0.33190000 \\
\hline $\mathrm{H}$ & 0.19542100 & -3.49014500 & -1.53353800 \\
\hline $\mathrm{H}$ & 1.32164300 & -4.29176400 & 1.32151700 \\
\hline $\mathrm{H}$ & 0.83654200 & -5.45233000 & 0.06243300 \\
\hline $\mathrm{H}$ & 3.06397400 & -6.56425800 & 0.21557400 \\
\hline $\mathrm{H}$ & 3.57362200 & -5.39260800 & 1.45272600 \\
\hline $\mathrm{H}$ & -7.59782400 & 0.76835100 & -0.55890000 \\
\hline $\mathrm{H}$ & -6.46451300 & 0.18340700 & -1.75316500 \\
\hline $\mathrm{H}$ & -7.03004300 & 0.91117200 & 1.63747900 \\
\hline $\mathrm{H}$ & -5.37130300 & 1.10632700 & 2.14517600 \\
\hline $\mathrm{H}$ & -7.96396300 & -1.66110200 & -0.96586400 \\
\hline $\mathrm{H}$ & -6.29331000 & -2.02042600 & -0.48952500 \\
\hline $\mathrm{H}$ & -7.44344700 & -1.40286900 & 0.70615100 \\
\hline $\mathrm{H}$ & -6.54091600 & 3.31827300 & 2.04795200 \\
\hline $\mathrm{H}$ & -5.24424300 & 3.28777200 & 0.83611500 \\
\hline $\mathrm{H}$ & -6.92828800 & 3.06443700 & 0.33930300 \\
\hline $\mathrm{H}$ & 6.26087500 & 3.35109800 & 0.15073800 \\
\hline $\mathrm{H}$ & 5.57373500 & 2.31003500 & -1.07191800 \\
\hline $\mathrm{H}$ & 4.94302100 & 4.77146400 & 1.36014400 \\
\hline
\end{tabular}




\begin{tabular}{|c|c|c|c|}
\hline $\mathrm{H}$ & 3.25763100 & 4.42292100 & 1.65085300 \\
\hline $\mathrm{H}$ & 6.43129100 & 4.43436400 & -2.08452400 \\
\hline $\mathrm{H}$ & 4.67043100 & 4.35827800 & -2.28680800 \\
\hline $\mathrm{H}$ & 5.37526100 & 5.38909200 & -1.03272400 \\
\hline $\mathrm{H}$ & 4.66584100 & 3.67716700 & 3.58217700 \\
\hline $\mathrm{H}$ & 3.92713500 & 2.25629400 & 2.81645300 \\
\hline $\mathrm{H}$ & 5.62671100 & 2.64399400 & 2.51303500 \\
\hline Si & -0.66111200 & 1.62458000 & 1.33774800 \\
\hline$C$ & -1.08245900 & 3.33425000 & 1.98986100 \\
\hline $\mathrm{H}$ & -1.22296300 & 4.04995400 & 1.17354900 \\
\hline $\mathrm{H}$ & -2.00133800 & 3.31615500 & 2.58730400 \\
\hline $\mathrm{H}$ & -0.28913100 & 3.71626400 & 2.64255100 \\
\hline$C$ & -0.40677500 & 0.39805600 & 2.74096100 \\
\hline $\mathrm{H}$ & -0.16503700 & -0.59936700 & 2.35902700 \\
\hline $\mathrm{H}$ & 0.41406800 & 0.71575200 & 3.39413200 \\
\hline $\mathrm{H}$ & -1.30950300 & 0.31225400 & 3.35632500 \\
\hline
\end{tabular}

